\title{
Innovation and its Contribution for a Hotel Product and its Online Presence
}

\author{
Subnu Perera \\ Buckinghamshire New University, UK \\ *Corresponding Author: subanuperera@hotmail.com
}

Copyright $($ ) 2014Horizon Research Publishing All rights reserved

\begin{abstract}
The purpose of this research is to analyze and review the dimensions of 'innovation' related to a hotel product while researching its contributions to a superior online presence. The significance of the study is to analyze: the degree of innovation, continuous innovation, innovation vs. renovation, validity, barriers and appropriateness of innovation for a hotel product. Here the online presence is also analyzed against the past, the present and the future while reviewing possible links which can be used to add value.
\end{abstract}

Keywords Innovation in Hospitality, Innovation, Innovation and Hotels

\section{Introduction and Research Problem}

\subsection{Outline of the Research}

The Chapter one provides an introduction to the research which includes: background analysis, research problem, scope and limitations.

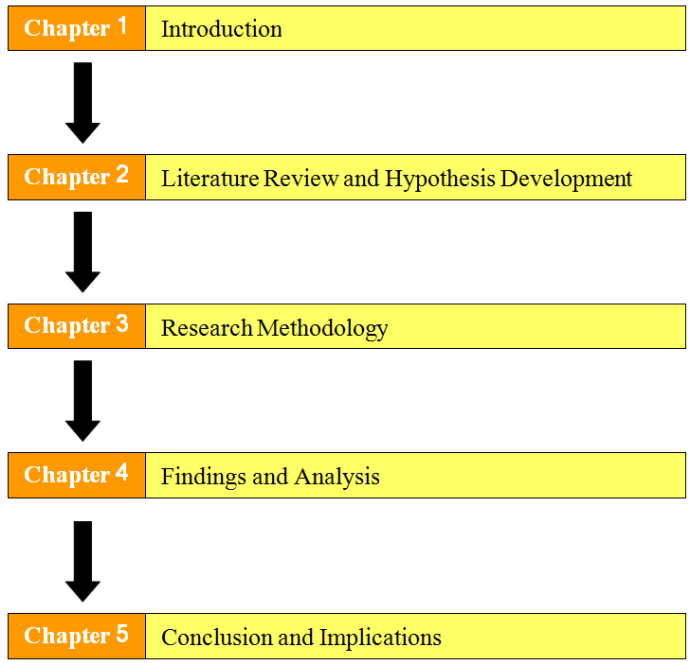

Source: Author's own source

Figure 1. Outline of the research

\subsection{Introduction}

The definition of a hotel according to the Colombia University Press [http://education.yahoo.com/reference/ encyclopedia] the term hotel is explained as [Fr., from O.Fr. (origin of Eng. hostel), from Latin (origin of Eng. hospital),=guest place]. The name was applied since the late $17^{\text {th }}$ century to an establishment supplying both food and lodging to the public which was then called as "Inn". Winslet (1970) explains that the term 'Inn' was later went on to be a 'hotel'.

From the available records "Hoshi", a traditional Japanese Ryokan (hotel), is listed in the Guinness Book of World Records as the oldest in the world.

In order to understand a 'hotel' product better it is vital for one to know the key areas in a hotel also.

Winslet (1970) describes a hotel to have the following key operational areas:

- Rooms Division: Areas covered are - Front Office, Reservations, Concierge, Communications (Telephone \& other), Housekeeping

- Food \& Beverage: Areas covered are - Specialty Restaurants, Table Services, Quick Services, Catering, Banquets, Clubs, Pubs, Coffee Shops \& Room Service

- Culinary/Kitchen Operation: The area involved in the preparation of food feasts for guests including: Restaurants, Bars, Bakery and Banquets.

- Other Operational Areas: Sales \& Marketing, Purchasing, Accounting and Finance, Engineering and Maintenance, Security, Human Resources

Although identified as individual areas, a hotel operation is a combination of the smooth functioning of all areas above.

Moving along with its traditional outlook, hotels have expanded to be an industry which has expanded in many different ways. Kotler and Keller (2006) defined the term 'core product' in the model 'Levels of a Product asKotler (2002) identified the core product of the hospitality industry as 'Rest and Sleep'.

Hence, hotels have managed to expand their own horizon, through effective development of the core products to its 
next levels, thereby offering uniqueness, attractiveness, competitiveness and marketability of a product.

Furthermore, the birth of the 'Internet' in the 1980's also increased competition between hotel products with information readily available around the clock, giving the customer the power to chose and purchase.

At the same time innovations took place in hotels in many other forms where there was competition for the largest, smallest, tallest, etc. hotel options around the world. Along with innovation and development the associated costs also went up subsequently.

\subsection{Background of the Study}

The purpose of this research is to analyze and review the dimensions of 'innovation' related to a hotel product while researching its contributions to a superior online presence. The significance of the study is to analyze the degree of innovation, continuous innovation, innovation vs. renovation, validity, barriers and appropriateness of innovation for a hotel product. Here the online presence is also analyzed against the past, the present and the future while reviewing possible links which can be used to add value.

\subsection{Research Problem}

Globally, a hotel product faces many challenges while being in operation. Challenges such as:

- The increasing costs in terms of material and labour and how innovation can help to maximize profits and improved processes.

- The limitations of buying power of prospective customers and it's relation to profitability.

- The shock of globalization and the rising competition

- The world is shrinking in to the palm of an average individual with the use of the internet rising by the day with generations of different classes expanding their access points, recurrence and dependability to the internet.

- Also it is seen that some of the hotel firms in the world have taken a very conservative approach to capitalize on its innovation and creating a value out of same.

The significance arises as the world expands in multiple forms and innovation becomes a mandatory option for the industry concerned. The research also highlights the vitality of being innovative.

The research is to help trace a better strategy and approach for a much improved online presence while the 'innovation' for a 'hotel product' adds value to an online and also offline presence/operation.

The hospitality industry with its own traditional outlooks of inns, hotels, boarding houses, guest houses, restaurants, tea-rooms, cafes, snack bars, canteens, etc. is expanding to cater in to the needs of the present and the future. However it is prudent to research as to if:
- the industry has been innovative enough to meet the needs of the present and the future

- the industry is keen to develop further and use the values of innovation to expand it's virtual boundaries

- The innovation is a tool for the development and expansion

- The dimensions of innovation is being mapped into a specific sub-segments [here it's hotels]

- The innovation is treated as continuous

- The avenues to use the strengths of innovation to enhance the online presence [focus on the hotel sub-segment].

In researching through and with the help of pre-determined sources of information, the target is to capture the contribution of innovation towards the development of online presence and possibly seek recommendations for a better approach of same.

\subsection{Limitation of the Study}

\subsubsection{Availability of Information}

- Innovations are closely guarded secrets of individuals/organizations until they are being given the right value or recognition. Therefore the study will not be able to capture any optimistic data on future innovations in the industry.

- All dimensions of an innovation may not be visible even after it is made public.

- Individuals and organization may believe their own standards on innovation. This will limit uniformity in data collection.

\subsubsection{Measuring Innovation}

Measuring of innovation can be considered to be a complicated exercise. Measurement is not only expected to value an innovation but also describe/asses its competitive position globally/regionally.

One such document which has been developed accepted and published by the OECD [Organization for Economic Corporation and Development] in May 2010. This is an effort to develop a much improved system towards the measurement of innovation in all aspects of same. However this has been developed to measure innovation in a specific country and to ascertain their competitive position of same.

Also, The European Innovation Scoreboard provides vital insight not only to measure innovation but also to be benchmarked as well.(see reference below)

\subsubsection{Barriers to Innovation}

In the European Journal of Innovation Management, Dobni (2008) offers an insight into the understanding of 'the barriers and related factors'. Krippendorff (2010) too analyzes the barriers and offers with some of the suggestions to overcome them. Although this study will not focus on the 'barriers in innovation' far in detail it will be considered a limitation factor. 


\section{Literature Review}

\subsection{Introduction}

Any industry is constantly requires innovation for both its product and service offering (Victorino, L. et al, 2005). At the same time the success of a firm depends on the attractiveness of the target market and the firm's ability to launch innovative services and products in response to same (Ottenbacher and Gnoth 2005). Therefore it can be argued the fact that the above two statements are valid for the hospitality industry/hotel products as well. The statements don not stop at this stage as it also confirms the higher competitiveness for a hotel product.

Adding to the above, hospitality industry/product to a customer can be perceived as a product which is often finds similarities and is an easily replicable product and service offering (Victorino, L. et al, 2005). This creates an unending challenging environment for the hotel to perform, be different (innovative) against its competitors and thereby generates more revenue out of higher demand/customer satisfaction. Therefore, expanding on innovation for a hotel product, it is argued further with the fact that 'innovation' itself is multi-dimensional (Dobni, C B., 2008).

Furthermore, information is acknowledged as the life-blood of tourism (O'Connor and Frew, 2002) as more availability of information expands customer motivation and ability to travel (O'Connor and Frew, 2002). Tourism products are by nature diverse, rarely purchased in isolation and can be combined with a seemingly endless range of permutations and combinations (O'Connor and Frew, 2002). This classic argument expands on the complexity of a hotel product and combined with some of the previous statement proves the rationale behind the strong importance of innovation and availability of information at all corners of the target audience/segment.

Combining all of the above this chapter will consist of several subsections which will discuss from some basic definitions of innovation in a hotel and thereby analyzing some of the models and theories available to best suite this research. At the latter part the model researched will be used to analyze various factors related to innovation for a hotel product and how it can relate/maximize on its online presence.

\subsection{Introduction: Theoretical Framework of the Study}

\subsubsection{Definition of a Hotel}

Kotler (2002) describes a hotel as a place where an individual or a group can rest and sleep. These are described as the core product of the hospitality industry.

\subsubsection{Definitions on Innovation}

The study is based on handpicked theories on innovation and the following theories will be adopted for the research process:

- "Innovation is the specific instrument that endows resources with a new capacity to create wealth" (Druker, 2007)

- All innovation must contain a degree of novelty which can be new to the market, new to the firm or new to the world - Source: OECD and Eurostat (2005), Oslo Manual

- Innovation is not an option, it is a fundamental requisite of survival - (Krippendorff, 2010)

- Innovations are "the carrying out of new combinations" (Schumpeter, 1971)

- "When an innovation takes place, there is an intimate linkage or fusion of two or more elements that not have been previously joined in just this fashion, so that the result is a qualitatively distinct whole" (Barnett, 1953)

- "Innovation: Location Matters" (Porter \& Stern, 2001)

Sources: as mentioned in the list of references and Colombia University Press-Encyclopaedia

\subsubsection{Selection of Models}

The research process demands the study of factors relating to a hotel product. The factors considered are e tangible benefit in comparison to a hotel where customer expectation is mapped against the product features. This will validate the options for a hotel manager to evaluate priorities for innovation. This is very important as Victorino, L. et al., (2005) explains, a hospitality product has the highest, yet easily substitutable service offering. Also a hotel product is conceptualized around various costs in terms of material and labour. As explained in the 'introduction' this is also a growing concern for hotel product with increasing costs needs to be stabilized against the demand for differentiation.

Therefore it is vital to understand the priorities which needs careful attention in analyzing the contributions of 'innovation' to the hospitality industry and thereby expanding on its online presence.

The key starts at the location where Victorino, L. et al, (2005) describes that to achieve the organizational goals is to achieve customer satisfaction more effectively than its competitors.

Also, both Victorino, L. et al, (2005) and Ottenbacher and Gnoth, (2005) discuss and agree on the importance of 'service' innovation and delivery. This is explained as the key to differentiation by both journals. Winslet (1973) in his book on Catering and Hotel operation also identify human (behavioural) related service design as the key to lead against competitors for a hotel product.

Therefore it is prudent to be strongly believe in achieving service excellence which then can be connected with innovation and focus on 'how' to be more effective and make information available via better online presence.

Therefore the research process will focus on the following key priority areas in this chapter in order to build up a much improved view point to support of the research objectives:

Analyzing the product and identifying key attributes related to the service aspect of a hotel: The model from Kotler, Amstrong and Wong, (1996) will be 
used primarily to discuss this.

- Identify the multidimensional innovation model and relate it to the product: The model suggested by Krippendorff, K., (2010) will be extensively used to analyze the model of innovation and its inter-relations. This will analyze a 'hotel' in the aspects defined earlier to link the service aspect and human interventions to identify the support factors for effective service delivery.

- Discuss on the innovation types: use model from OECD (2006) to discuss on the innovation types and its usage for a hotel product.

- Innovative position: The new model developed for this purpose will be used to find the rationale behind organizations and their attitude towards innovation. This model was developed by the author to satisfy the need of a matrix to identify the position of an organization against innovation. This simple matrix offers an easy to understand definitions for various organizational types. Once a position is identified the same can be matched against the strategic direction of the organization. However it must be understood that this matrix will only provide a more 'macro' level analysis while a more standardized option may be available. However the model suggested satisfies the need of this research.

- Combine the findings of the above priorities to identify the path to link it to support to achieve a superior online presence: However as per the research which covered prestigious associations such as 'IEEE', etc. a regionally/globally standardized online model was not found. In most of the cases certain business entities and institutions used their own in-house model/standard for websites. In such cases a very descriptive, yet finely standardized website managing model was found from the Harvard University. However it is noted that technology represents an important strategic asset in obtaining competitiveness (O’Connor, 1999) also for a business. However as this survey only covers on the contribution of innovation towards superior online presence, the analysis is not expected to provide a clear indication as to how innovation can be more effectively presented online. Yet the author considers it to be a very important area and will cover some of the basic aspects of e-commerce to partially fulfil the requirement.

\subsubsection{Model 1: Levels of Product}

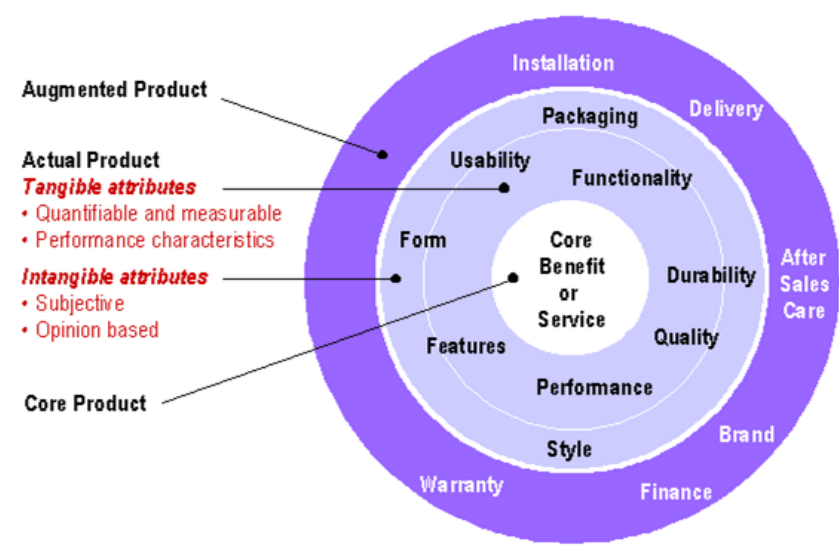

Source: Kotler, Amstrong and Wong, (1996)

Figure 2. Levels of Product

2.2.3.2. Model 2 Evolvement \& Management of Innovation

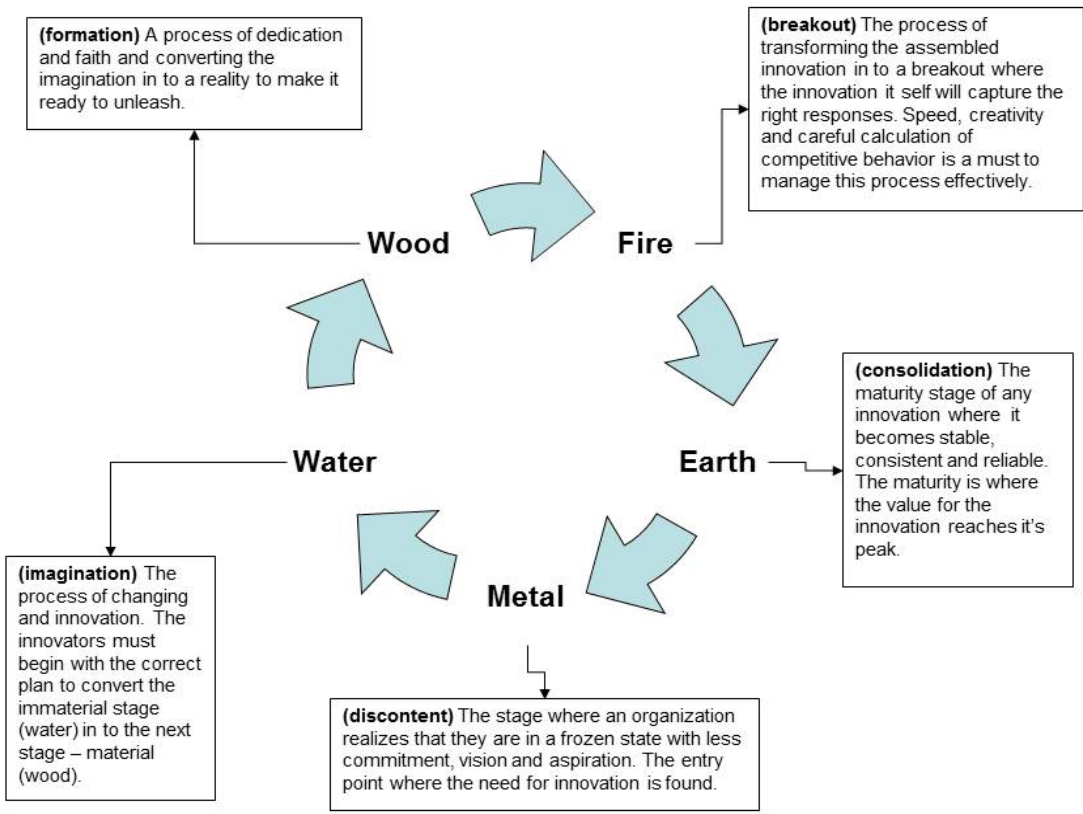

Source: Krippendorff, K. (2010)

Figure 3. Evolvement \&Management of Innovation 


\subsubsection{Model 3 Types of Innovation}

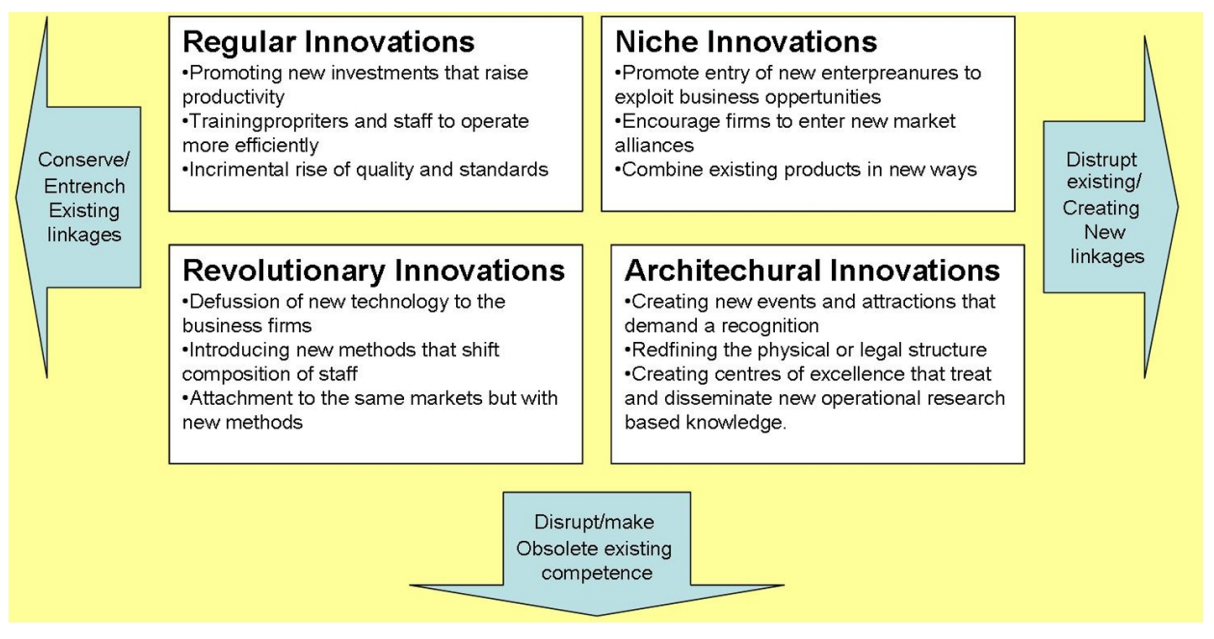

Source: OECD (2006)

Figure 4. Types of Innovation

This specific model is quoted from an OECD publication named, Innovation and Growth in Tourism. As per the mentioned sources in the publication this is an adaptation of the original model from Abernathy and Clark (1985) and later expanded by Hjalager (2002, p.467) to suite the tourism industry in general. The original model has been re-visited, analyzed and modified to better fit the aspects of tourism and to provide a model which can relate more for a specific industry.

This model concentrates more on types of innovation which can exist. Therefore it will be vital to discuss what types of innovation should be prioritized for a hotel product.

\subsubsection{Model 3 The Innovation Window (Innovativeness)}

Innovation window is a model developed through the use of quoted references in the given annexure.

This model was developed to understand the positioning of an entity as against innovation. This position varies with individuals/teams/organizations and is described as the direction they are in.

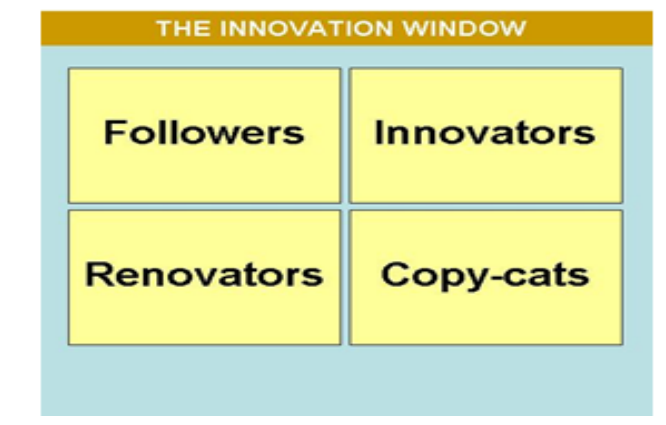

Source: Subanu (2010)

Figure 5. The innovation window

The purpose of introduction of the above model is to identify and segregate individuals/ organizations in relation to their approach for innovation.

\begin{tabular}{|c|c|}
\hline Category & Description \\
\hline Followers & $\begin{array}{l}\text { No interest in innovation. } \\
\text { Conservative approach. }\end{array}$ \\
\hline Renovators & $\begin{array}{c}\text { Create extensions of innovations or expanded versions } \\
\text { of existing innovations. } \\
\text { At times this may/may not compliment the existing } \\
\text { innovation. }\end{array}$ \\
\hline Copy-cats & $\begin{array}{l}\text { Experts in copying existing innovations. } \\
\text { Quality may be compromised in a copy. } \\
\text { Chances of the copy not being identical. }\end{array}$ \\
\hline Innovators & $\begin{array}{l}\text { Leaders } \\
\text { Innovation takes place on a continuous basis. }\end{array}$ \\
\hline
\end{tabular}

\subsection{Analysis Based on the Models Selected}

\subsubsection{Model 1 Levels of Product}

Kotler, Amstrong and Wong, (1996) defined this model to support a broader analysis of a given product. Whenever one seeks avenues to strengthen a product, the beginner analysis through this model provides a greater insight in to the product and its attributes.

The core product as explained in an earlier section define 'rest and sleep' as the prime feature of a hotel product Kotler (2002). A customer among his/her other likes and dislikes will look for these basics before resting. However as Victorino, L. et al, (2005) correctly explains, much of the service offerings are substitutable for a hotel product, the analysis needs to be escalated to the next level where an analysis on the actual product/expected product may be used.

A customer demands for more than 01 of the product features as listed below (source: self research):

- Facilities available (e.g. number of rooms, room facilities and hotel facilities, etc.)

- Location (e.g. on the beach, next to a key attraction or in the city centre, etc.)

- Accessibility (e.g. distance from the airport, etc.) 
- Star classification

- Flexibility and customer friendliness (e.g. in reserving a room, selecting what the customer needs, etc.)

- Attention to detail and proactive-ness

- Services available (e.g. 24 hour concierge, etc.)

The 'expected product' out of a hotel product was identified after a mini-research process covering 03 hotel products in Sri Lanka. This was conducted through 02 focus group meetings held separately covering two of the key stake holders of a hotel namely (i) hotel managers (ii) customers.

This was conducted not only to identify possible attributes of an expected product but also to assess the contribution of tangible and intangible assets for an expected hotel product. As human capital is not considered a tangible asset (Richard and Bill, 2006) it was allocated to the intangible section along with its own related features of the expected product.

Analyzing this, even if you consider the above findings, out of the 7 there are 3 directly human related aspects which are intangible. Therefore it can be observed that an intangible asset such as the human capital can make a difference for a hotel product. Ottenbacher, M., and Gnoth, J., (2005) identified the staff as a key resource in delivering and optimizing on innovation aspect of a hotel. As explained earlier, if a hotel is pressured for continuous innovation, it is noted that limitations may exist to use tangible assets due to cost, etc. This is one key reason for Ottenbacher, M., and Gnoth, J., (2005) to pick services innovation as a superior alternative while using innovation champions (Ottenbacher, and Gnoth, 2005) which are - staff.

The product level beyond this point reaches the augmented product which is intangible to measure but can add value to the existing operation. In using a living example, certain hotels use the term 'experience' (e.g. www.starwoodhotels.com) where a guest is offered with a one of a kind dream experience (e.g. The Westin Diplomat Resort \& Spa, Hollywood, Florida). Another example for a similar intangible aspect is to be a 'greener hotel' (e.g. http://www.heritancehotels.com/kandalama/) which offers an environmentally friendly greener accommodation focusing on nature lovers to entice the hotel. However it is noted that 'experience' is a subjective and comparable option which needs careful plan prior to implementation.

This has been discussed on the OECD (2006) and has written as a fact. However the author believes and suggests that an experience maybe seen as novel to a guest unless you continuously innovate within the experience also. The affects of the experience may be limited to the number of nights spent and number of free hours spent at the hotel also.

The author wishes to suggest that no 'experience' is worth if the guest has no adequate time to experience. This suggestion is based on a study carried out using the guest satisfaction forms of Heritance Ahungalla and Heritance Kandalama hotels in Sri Lanka (www.heritancehotels.com)

In summarising the above the following can be explained:

- It is vital for an organisation to understand the Levels of Product in order to map innovation tin to various levels of the product.

- Innovation can have its own limitation when it comes to a hotel product. Therefore service innovation will be the best available choice to be above the rest.

- Employees of a hotel have a larger responsibility and stake over innovation where outstanding individuals can offer significant contributions for such innovations.

Based onthe above discussions and relating to the theory, the followings can be hypothesized:

- Hypothesis 1: Innovation aspect for a hotel product is to concentrate more on service innovation

- Hypothesis 2: Most crucial aspect of new service innovation is employees of a hotel

\subsubsection{Model 2 Evolvement and Management of Innovation}

Krippendorff, K. (2010) offered this model combining the philosophical teaching of 'Five Aggregates' in Buddhism and the relating to the real world experience with the theories suggested by Sun Tzu's, The Art of War. Krippendorff, K. (2010) successfully combined the two to create a framework which will not only suit the modern day business environment but also to offer a deeper analysis of the multi-faced innovation and its related aspects.

The process starts where that an organization realizes that innovation is essential for survival (OECD, 2006). However one has to reassure that an innovation is required for an economical benefit to an organization and not just increase another cost for an organization (Victorino, L. et al., 2005). Therefore innovations are not only for the customers who deserve them but also for the benefit of the organization in economical terms (Victorino, L. et al., 2005).

Furthermore, a hotel product as described in previous sections has limitations in being innovative in their tangible assets such as location, etc. Although in certain cases it can be expanded, innovativeness on tangible assets incurs higher costs which might require time to recover (OECD, 2006). However the author does not iron out the fact that tangible assets may be used for innovation also, but it is natural to be aware that the return on investment might be longer. Therefore for a hotel product, the wisest approach will be to prioritize on service and process innovation.

However it is noted that it will be easier for one to identify the need for innovation for a tangible asset to an intangible asset. Therefore it will be good to understand ways and means of understanding the need for innovation for services and processes. This requires powerful commitment, vision and aspiration and knowing the current situation (Krippendorff, 2010). Once again this relates to the scenario developed by Ottenbacher and Gnoth, (2005) of having 'innovative champions' in an organization. This is a challenging option as most organizations do not even know that they have a need for innovation (Krippendorff, 2010).

Krippendorff (2010) refer to another publication by Sun Tzu, a Chinese philosopher who wrote a book named Art of War in 1910 discussed earlier. Although his book refers to 
tactics in the act of war, Krippendorff (2010) has followed the path of the book in his framework and has used proverbs from it frequently suggesting and recommending its use for modern day business (also). This book too highlight the importance of a good leader for an army (business) and mention "Hence the skilful fighter puts himself in to a position which makes defeat impossible, and does not miss the moment to defeat the enemy" stressing the importance of leadership and skills.

Once the need for innovation is discovered, then the need for imagination comes in. Here the crucial aspect will be to think freely and independently from the traditional structures and formalities. This will be a challenging task as the hospitality industry is considered traditional and which itself limits its scope to do better.

Therefore a powerful hotel manager can un-wire the traditional links and drive a team towards innovation. This is where the innovation will take place.

The model explains the next stage as 'fire' which is described as the breakout stage Krippendorff, (2010). This can be an ideal stage where careful planning can bring in extraordinary results. This is where the point where the innovation endows resources with a new capacity to create wealth (Druker, 2007).Therefore a careful environmental (competitor) analysis would make this stage a much stronger (Krippendorff, 2010) which will return better financial gains. It is understood that this stage is not about launching an innovation but also a stage where final touches are made through intelligence on competitors and their behaviours, further analyzed and matched against the capabilities of the innovation to make it stronger.

This is stage where the innovation will have its highest response. Therefore as Victorino, L. et al, (2005) explains that the best time to capitalize the innovation to generate revenue is before the service of a hotel product is copied.

Everything around us has an expiry date (philosophical teaching of Buddhism). As per the analysis a hotel manager must know that a hotel product's innovation may have a fairly shorter life span and get copied. Therefore it is vital to understand the shift of the innovation from the 'fire' to 'earth' stage.

Fire is the settling down and maturity stage where the innovation reaches its peak levels of response (Krippendorff, 2010). Much more than the innovation stage Krippendorff, (2010) explains that this as a very important stage to know where the innovation stands in order for the hotel, it's now times to re-initiate the 'innovation' process from the beginning.

This model not only analyzes and discusses the evolvement and management of innovation but also highlight an important aspect related to a hotel product. This is needed for an active innovation culture in a hotel incorporating all employees/key stake holders.

Dobni, (2008) in his research on innovation culture has very strongly and justifiably analyzed a strong relationship between innovativeness and the culture. Adopting organizational innovativeness as "the organization's overall innovative capability of introducing new products in to the market, or opening up new markets, through combining strategic orientation with innovative behaviour and process" from Wang and Ahmed (2004). Also, Dobni, (2008) discuss of a strongly bonded, yet multi-dimensional aspects of innovation culture (innovativeness) in an organization.

This is quite a crucial, important link and a fact for a hotel product (as analyzed through) as a well established innovation culture with the right vision can add value to a hotel enormously. Therefore along with evolvement and management of innovation, it will be a strong analysis to associate how a hotel product can benefit an innovation culture.

Dobni, (2008) explains of the dimensions of 'innovativeness' quoting the analysis from Wang and Ahmed, (2004):

- Product

- Market

- Process

- Behaviour

- Strategic innovation

Also Dobni, (2008) further analyze the organizational culture with key capabilities which are identified as

- Market sensing

- Customer linking

- Competitor sensing

- Customer services

- Technology development

- New product/service development

- Organizational communication

Culture in an organization is governed by values and believes of the employees. This is always a top down responsibility and a vision which needs to be gifted from the top level down. A hotel product needs to be understood from the aspects of organizational culture very carefully to embed a very strong, yet productive culture in to a system. A well balanced organizational culture influences creativity and innovation Dobni, (2008).

Also, an organizational culture is very important for a service oriented product such as a hotel as it deals with an intangible product. These factors will drive a hotel towards continuous innovation which will help to it to differentiate from its competitors.

Dobni, (2008) in his research suggest certain aspects which an organization can adopt to achieve an effective organizational culture which would strongly assist an organization to be better with innovation and creativity. They are:

- Value creativity : if the organization sees a value for it, the employee also benefits from it

- Take risk: deal with risk positively as a team.

- Freedom: freedom is one aspect an employee will greatly require to be creative and innovative.

- Team work: None of the factors will work together and offer a better option if everybody does not think together and carry one vision/dream. Therefore team work is very important. 
- Be solutions oriented: in the service industry specifically, customers need effective solutions which will not only contribute positively for a great stay but also for the product attributes.

- Good communication: good communication will leave no space for errors and misunderstandings and will also create sense of belonging

- Encourage trust and self respect: the aspect which can contribute greatly to create a motivated, stronger team

- Faster decision making cycle: as analyzed in this research, a hotel product which is greatly substitutable, needs a faster decision making process with delegation and authority.

Incorporating the research from Dobni, (2008) it is suggested that a hotel manager can also be aware of certain barriers to innovation and be prepared with methodologies to overcome them.

Some of them are:

- Fear of change

- Knowledge barriers

- Rigidity

- Over-weighted controls

to name a few.

In summarising the above the following can be explained:

- Innovation is a continuous process which has its own Life Cycle.

- The crucial aspect in innovation for a hotel is to understand 'the need' to be innovative. This may have it own reasons such as to be ahead of the competition, etc.

- Innovation has to be managed, is multi-dimensional and has limitations even for a hotel product.

- Organisational culture is a crucial aspect to achieve higher results in innovation.

Based on the above discussions and theory (and the related aspects), the followings can be hypothesized:

- Hypothesis 3:The most crucial aspect for a hotel product is to comprehend the 'need' to be innovative

- Hypothesis 4: Organisational Culture is of highest importance to achieve higher results in innovation.

\subsubsection{Model 3 Innovation Types}

Model - 1 was used to identify various levels of a hotel product and it's key priorities, model -2 was used to analyze how a hotel product can benefit out of the evolvement and management of innovation which connects itself with the contributions of an innovative culture in a hotel.

The model "Innovation types" focuses on 04 types of innovation and their variety and applicability for a hotel product. This process is vital to perform because identifying the right type of innovation for a hotel product is a useful exercise for prioritization. The model covers not only the types of innovation but also offers insight in to the direction (where innovation is heading towards) as well.

This specific model is quoted from an OECD publication named, Innovation and Growth in Tourism. As per this publication, it is an adaptation of the original model from Abernathy and Clark (1985) and later expanded by Hjalager (2002, p.467) to suite the Tourism industry in general. The original model has been re-visited, analyzed and modified to better fit the aspects of tourism; and to provide a model which can relate more for a specific industry.

In the earlier sections it was discussed that hotel products can differentiate and be more innovative in the 'service and processes. Also as mentioned earlier the model provides a direction for the innovation as well. This makes this model a very simple, yet informative thus making applicability very high.

Therefore, with regard to the model it can be analyzed that Architectural innovations are most related to tangible innovations where a physical or legal structure is associated. In this scenario hotel product would have higher limitations as this type of innovation related to a hotel can be costly and not viable in financial terms. A classical example would have been to be architecturally innovative at the beginning of a hotel product and may be at a later refurbishment stage. However the returns may be long term and will have limitations.

Niche innovations are related to extensions of products which can be used to the value of a hotel product. For example, an existing hotel can sign up with an internationally recognized brand, etc. Both architectural and niche innovations (type) carry 01 common aspect is that both these types do not support continuous innovation which is accepted as a mode of survival for hospitality products. Therefore both these two types will have limitations of its own when it comes to a hotel product and will not be high priority when it comes to innovations.

Also, Hotel products are closely inter-connected with various processes, systems and controls which are primarily executed and monitored through human intervention. Therefore there is much provision for improvements exist. Regular innovations therefore are much valid for a hotel product where regular aspects of the operation are improved/expanded through the use of innovation. Regular innovation does not necessarily require higher funding concerns and offers short term returns on the time and funds invested. Hotel services being easy substitutable can make use of regular innovations responding to internal and external demands available for innovation. Internal innovations have space for improvement (Victorino, L. et al., 2005). Therefore the innovation not only will benefit for internal stakeholders but also the end customers indirectly.

Revolutionary innovations are generally one of those situations where a brand new innovation is introduced to a hotel. This can be by the means of technology, new methodologies a feature or aspect which will trigger higher attention of a specific segment. For example, guests when they stay they earn carbon credit where they can use it against their emission taxes on airfare, etc.

Both regular and revolutionary innovations fit in with the requirement of fast changing and continuous innovation needs of a hotel. 
In summarising the above the following can be explained:

- There are four types of innovation exists. A hotel product needs to asses it self against the types of innovations available to finds the best suitable and alternatively suitable, etc. to gain an advantage over innovation.

- Innovation is related not only to tangible assets but also for intangible assets also.

- Innovation is not only related to 'technology' for a hotel product. However technological innovations too can be of help for a hotel.

- A hotel must be innovative not only to be ahead of the competition but also for reasons such as cost saving, improved processes, improved response time, etc.

Based on above discussions and relating with the theory and the related aspects, the followings can be hypothesized:

- Hypothesis 5: A hotel product needs to understand the types of innovation which can be adopted.

\subsubsection{Model 4 The Innovation Window(Innovativeness)}

The innovation window was developed using the essences of two models namely: The Evolvement and Management of Innovation by Krippendorff, K. (2010) and the Framework of Innovation Types by OECD (2006). While analysis through the above 02 models it was made aware that an organization needs to understand where they should position themselves in terms of innovativeness.

This can be categorized as very important as not all hotel products may be able to adopt all innovation types and also will be forced look at alternatives. The model satisfies the need for an organization to be aware of their direction on innovation in general and for specific projects.

The model does not provide any insight as to which strategy fits in and for which project. Therefore it is the organization which needs to ascertain the internal situation, the potential and the market conditions prior to selecting a suitable strategy.

However depending on the characteristics of the physical product (hotel) a approach can be defined for a given period as approach itself can position a hotel product.

For example if it is an ordinary city hotel with less provision for innovation exists, you may continue to copy what others do. For example, opening up a specialty restaurant which another hotel is offering and is generating more customers and revenue.

There are advantages as well as drawbacks of this model and which will be of beneficial to analyze from the perspective of a hotel product.

In summarising the above the following can be explained:

- A hotel not only required to know what types of innovation to be used/prioritised but also the level of innovation as well.

- The selection is based on internal/external factors and is subject to continuous review for a pre-agreed period.

Based on above discussions and relating with the theory and the related aspects, the followings can be hypothesized

- Hypothesis 6: A hotel product needs to gauge its level of innovation

\subsubsection{Contribution of Innovation towards Online Presence}

As mentioned previously, the existence of a hospitality/hotel based web model was not perfectly found. However, online presence has a higher potential to make information and reservations at a relatively low cost (OECD, 2006). Here online presence is being described as having the highest potential to reach a very large audience where some of the traditional mediums are unable to reach customers around the clock. It is not only for the customers but also suppliers and intermediaries as well.

Table 1. Advantages and Disadvantages of Innovation levels

\begin{tabular}{|c|c|c|}
\hline Followers & Advantages & Drawbacks \\
\hline Innovators & $\begin{array}{c}\text { Very competitive and is ideal for a hotel product. } \\
\text { Often challenge the competition and is the first in the market }\end{array}$ & $\begin{array}{c}\text { Competitiveness may be low and therefore might have to } \\
\text { compete on price and often be pressured from } \\
\text { competition. }\end{array}$ \\
\hline Renovators & $\begin{array}{c}\text { The cost of renovating an existing innovation to make it look } \\
\text { different. Therefore the cost is comparatively lesser than innovating. }\end{array}$ & $\begin{array}{c}\text { The end customer may not see a real value addition of } \\
\text { the renovated product/service. }\end{array}$ \\
\hline Copy-cats & Only the cost of copying. & $\begin{array}{c}\text { Substitutable strategy which may not be suitable for all } \\
\text { types of hotel products (e.g. budget, luxury, boutique, } \\
\text { etc.) and must be analyzed prior to selection. }\end{array}$ \\
\hline
\end{tabular}




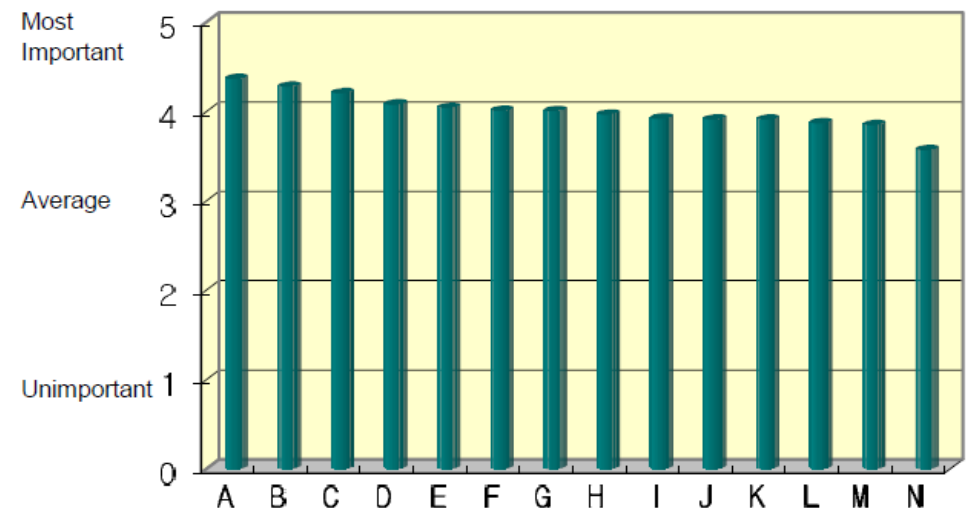

\begin{abstract}
A: Providing easy access to information on tourism products and services; B: Providing better information on tourism products and services; $\mathbf{C}$ : Providing convenience for customers; $\mathbf{D}$ : Expanding choices by customers; E: Creating new markets; F: Establishing interactive relationship with customers; G: Improving customer services; H: Improving image and public recognition of the small \& medium sized tourism enterprises; I: Saving time for providing tourism services; J: Providing customized \& specialized tourism products \& services; $\mathbf{K}$ : Reducing operating cost; $\mathbf{L}$ : Simplifying the process business; M: Interacting with business partners; N: Founding new business partners.
\end{abstract}

Source: OECD (2006)

Figure 6. The Benefits of E-commerce

In the simplest form, a website will have three layers (Shklar and Rosen, 2007) and they are namely: the (i) the presentation layer (ii) the application layer (iii) the database layer. All this forms a functional website application. Although there are 03 layers, a customer/stake holder will not necessarily be exposed to the other layers which are very important in order to have a fully functional presentation layer (Painter, 2007). Online presence is also linked to e-business or e-commerce for a hotel website (Painter, 2007). E-commerce provides easy, around the clock access to customers (Painter, 2007).

Benefits of e-commerce are highlighted in the following figure and provide a very valuable research input which prioritizes on online strategies for a hotel product (OECD, 2006).

The above graph provides valuable insight as to how an online presence can help a tourism product.

A successful website requires the commitment from the top management of a hospitality product to believe in the ever expanding online communities (OECD, 2006). It is with the commitment of the top management that a hotel product is able to position an innovative strategy which can be then linked with the online strategy. This connects the two as the innovation strategy will remain common to both.

Once an innovation strategy is defined, it is vital to analyze its association with the online presence so that the innovations can be used not only to compliment the online presence but also to be innovative online as well.

Customers looking for information on hotel products prefer to be comfortable with user friendly websites with simple layouts (Painter, 2007). Higher downloading time, complicated functionalities and highly technical attachments may not be welcoming for customer segments (Painter, 2007).

Therefore no better model exists for a hotel web model and is purely customer centric operation. However supplementary options such as Search Engine Optimization (SEO), linking with $3^{\text {rd }}$ party website and advertising on $3^{\text {rd }}$ party websites can be used as tools to expand on the online presence. It is vital to understand that online presence is not only about the hotel website but also other websites also holding information and links of the hotel product. This makes it important to manage innovations also across to maintain consistency.

Innovation of a hotel product can be used to add value to the online presence of a hotel in several different ways. One aspect would be to reach the online community which may be not aware of an innovation in the first place. Another aspect would be to communicate the innovation to an existing base of clients. This may be even a service innovation or a physical product innovation. The potential customers need to be aware of it; and online medium is simply an affordable medium which is accessible.

Being innovative online is another aspect for a hotel product. This refers to all direct and indirect online presence of a hotel product as mentioned earlier. It refers not to a bundle of new technologies, animations, etc, but merely a customer friendly online presence which can satisfy the general customer (OECD, 2006).

Research (customers and online presence) as well as benchmarking can help a hotel product to be innovative online. Continuous research on the positioning helps to track trends and new markets. Customers who search for information on hotels do look for what other customers say about the product as well. Therefore it is also much important to manage reviews of a hotel product also.

Through the own research of the author, the following figure was designed considering a key aspect for a hotel website. These aspects contribute to the success and superior online presence. 


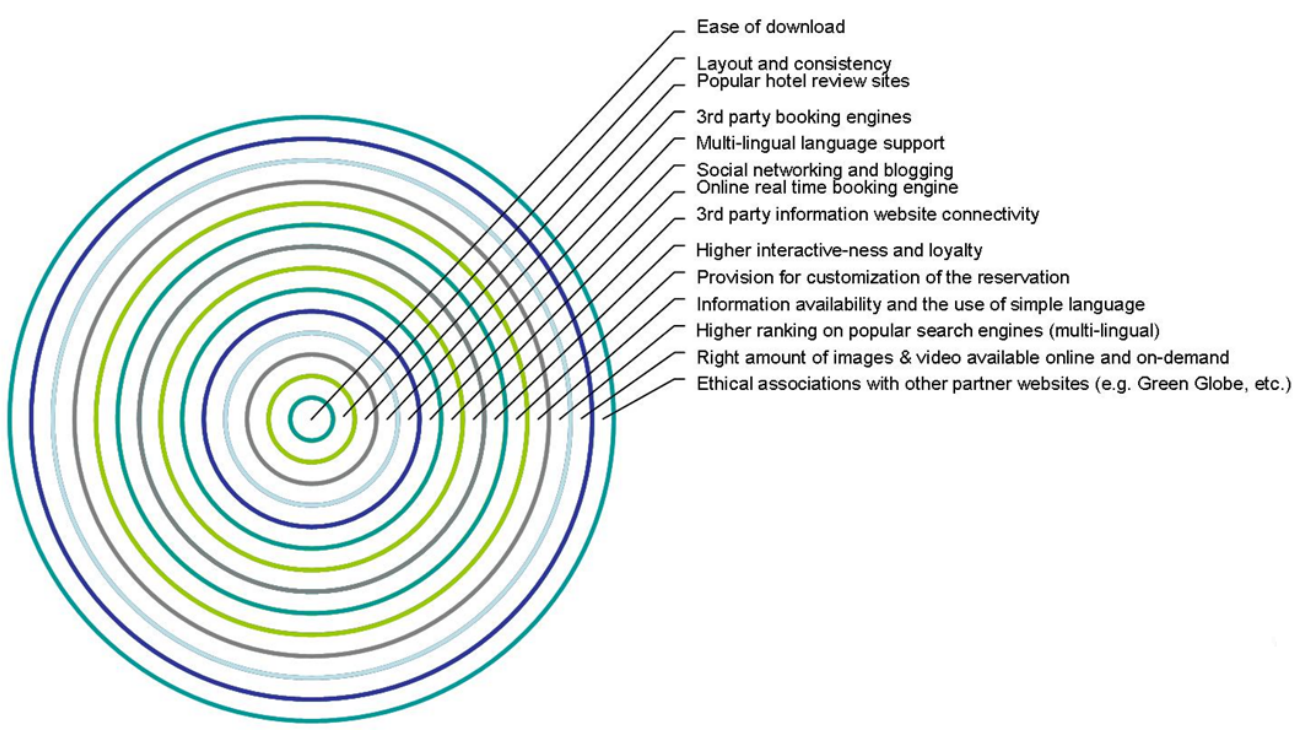

Source: Authors own source

Figure 7. Contributory Aspects for Superior Online Presence

The following table analyzes each aspect briefly in support of the research:

Table 2. The Significant Characteristics of Contributing Aspects for Online Presence

\begin{tabular}{|c|c|}
\hline The aspect to consider & The significance \\
\hline Multi-lingual language support & $\begin{array}{l}\text { This is required to reach across geographical boundaries to } \\
\text { talk the same language across borders. }\end{array}$ \\
\hline Right amount of images available online and on-demand & $\begin{array}{l}\text { Too many images makes it slower to download. The right } \\
\text { amount of images to capture the essence of the hotel together } \\
\text { with a good collection of on-demand (additional images) } \\
\text { which may be required as a picture gallery, etc. }\end{array}$ \\
\hline Information availability and the use of simple language & $\begin{array}{l}\text { Information available to be up to date with the right content } \\
\text { and (it is) safer to use a simple language. Writing should not } \\
\text { offend any belief, religion or group, etc. }\end{array}$ \\
\hline Layout and consistency & $\begin{array}{l}\text { Simple easy to navigate layout which tells you where you are } \\
\text { and offers you quick information and more information on } \\
\text { demand. }\end{array}$ \\
\hline 3rd party information website connectivity & $\begin{array}{l}\text { Connectivity to 3rd party websites to create expandable } \\
\text { online presence. }\end{array}$ \\
\hline Online real time booking engine & $\begin{array}{l}\text { The customer once convinced should have a hassle free } \\
\text { booking procedure. }\end{array}$ \\
\hline 3rd party booking engines & $\begin{array}{l}\text { This is required to expand the e-commerce reach and } \\
\text { markets. }\end{array}$ \\
\hline Popular hotel review sites & $\begin{array}{l}\text { Hotel reviews are increasingly popular among many tourists } \\
\text { as they speak of their real experiences. }\end{array}$ \\
\hline $\begin{array}{l}\text { Ethical associations with other partner websites (e.g. Green } \\
\text { Globe, etc.) }\end{array}$ & $\begin{array}{c}\text { Ethical associations are increasingly becoming important. } \\
\text { Guests not only look for a great hotel but also look for hotels } \\
\text { with better sustainable and ethical practices. }\end{array}$ \\
\hline Higher ranking on popular search engines (multi-lingual) & $\begin{array}{l}\text { Search engines are not uniform. Therefore it is important to } \\
\text { maintain good ranking across and in languages the target } \\
\text { audiences speak and local popular search engines they use. }\end{array}$ \\
\hline Social networking and blogging & $\begin{array}{c}\text { Socializing online where these communities are expanding. } \\
\text { Therefore active presence is vital. }\end{array}$ \\
\hline Highly interactive and loyalty & $\begin{array}{l}\text { Higher interactivity leads to loyalty and loyalty leads to } \\
\text { more business. }\end{array}$ \\
\hline Ease of download & $\begin{array}{c}\text { This is one crucial aspect of a website for a hotel. Download } \\
\text { speed does matter for a customer and gives the first } \\
\text { impression of the online presence also. }\end{array}$ \\
\hline Availability (of the website) $24 \times 7$ & $\begin{array}{l}\text { We deal across time zones and therefore it is vital that the } \\
\text { website to run } 24 \times 7 \text { non-stop and with adequate backup } \\
\text { facilities in case of a failure. }\end{array}$ \\
\hline Provision for customization of the reservation & $\begin{array}{l}\text { We all love to customize our own room, own meal and own } \\
\text { environment. Customization helps to build stronger ties as } \\
\text { the more you customize more closer it will be for a customer. }\end{array}$ \\
\hline
\end{tabular}


Table 3. Summary of Hypothesis

\begin{tabular}{|l|r|}
\hline Hypothesis 1: & Innovation aspect for a hotel product is to concentrate more on service innovation \\
\hline Hypothesis 2: & Most crucial aspect of new service innovation is employees of a hotel \\
\hline Hypothesis 3: & The most crucial aspect for a hotel product is to comprehend the 'need' to be innovative \\
\hline Hypothesis 4: & Organisational Culture is of highest importance to achieve higher results in innovation. \\
\hline Hypothesis 5: & A hotel product needs to understand the types of innovation which can be adopted. \\
\hline Hypothesis 6: & A hotel product needs to gauge its level of innovation \\
\hline
\end{tabular}

Online strategy is a key term is online business operations (Shklar and Rosen, 2007). Therefore the online strategy must be defined in consultation with all related aspects in support of the entire online presence of a hotel product. The strategy once in place must leave provision for continuous improvement. A typical online strategy will cover the following:

- The period of validity of the strategy

- Research and review policy

- Policy for 'own' site including use of technology, images and content

- Policy for $3^{\text {rd }}$ party sites use of technology, images and content

- Policy on E-commerce of online presence (own site and $3^{\text {rd }}$ party sites)

- Benchmarking policy

- Innovation policy

Source: authors own source

In summarising the above the following can be explained

- A range of reasons and advantages exists for a hotel product to be online.

- A clearly defined online strategy provides a real value/return to the organisation and must be offering space for continuous improvement as well.

- Top-down management commitment is vital for a hotel to achieve superior online presence

- Hotel websites should have up to date information and sufficient amount of information available.

- There are advantages of having online, real-time booking engines for a hotel.

- Online presence for a hotel product refers not only for its own website but also $3^{\text {rd }}$ party sites as well.

Based on above discussions and relating with the theory and the related aspects, the followings can be hypothesized:

\subsection{Summary of Hypothesis}

A summary of the hypothesis defined in the literature review is mentioned below:

In defining the above mentioned hypothesis the model suggested by Cooper and Schindler (2008, pg. 46) on 'checklist for developing strong hypothesis' was used.

\subsection{Research Purpose and Approach}

Cooper and Schindler (2008) define that good researcher generates dependable data that are derived by professionally conducted practices and that can be used reliably for decision making. This is elaborated further by Cooper and Schindler (2008) in their model 'what actions guarantee good business research?' and offers a valuable starter to a research process with clear guidelines covered by same.

Also, descriptive research has been popularly defined by Punch (2000) as the collection, organization and summarization of information about the research problem and issues identified in it.

The primary objective of this survey was to research the dimensions of 'innovation' related to a hotel product while research on its contributions to a superior online presence. Therefore the research purpose will be to analyze collected quantitative data, examine the data available using a tool such as Microsoft Excel and critically examine of the problem and draw-up recommendations/conclusions for same.

Although the research is based more on the behaviour of descriptive research in view of complimenting and better analyzing some of the related behaviour a limited use of explanatory research is also used.

At this stage the research approaches available to be analyzed as Creswell, (2003) explains is that the selection of a research approach as a very crucial decision in this process where it offers the right approach to critically evaluate the various approaches that will contribute to the success of the survey.

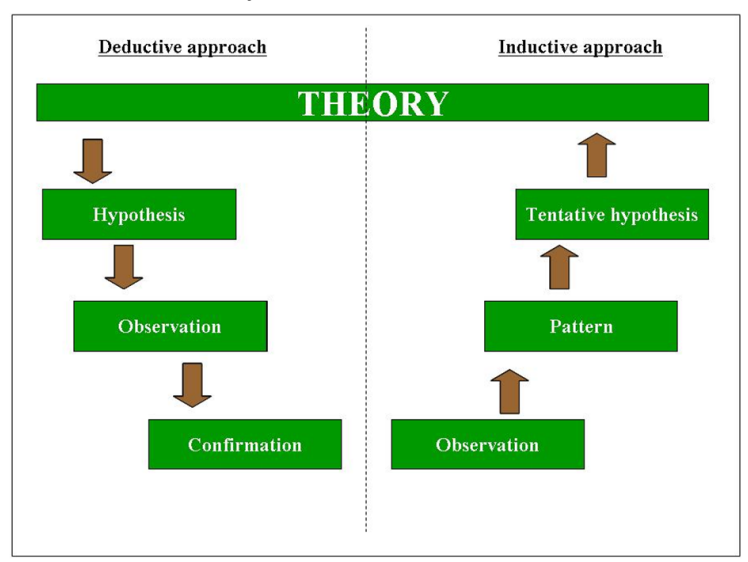

Source: Adopted from Creswell, (2003)

Figure 8. Deductive and Inductive Approaches to Research

\section{Research Methodology}


Therefore the following is a combined model from Creswell, (2003) and which was pictorially developed to summarize the two research approaches and to offer a start to evaluate same.

\subsubsection{Deductive Approach}

Cooper and Schindler (2008) define the Deductive Approach as a form of argument that purports to be conclusive. The conclusion must necessarily follow from the reason given. These reasons are said to imply the conclusion than is found with induction. This research has similar behaviour to the Deductive Approach.

This statement can be further proved as the research has compared a set of pre-identified theories / models. Then it has analyzed and applied the most suited theories and models which were followed by defining a set of hypothesis and to be tested with the findings of the research.

\subsubsection{Quantitative Approaches}

Cooper and Schindler (2008) define Quantitative Research/Approach as an approach which attempts to precisely measure something. Cooper and Schindler (2008) also explain that such methodologies answer questions related to how much, how often, how many, when and who?

The framework provided by Cooper and Schindler (2008) which distinguish the features of the quantitative and qualitative approaches. In the model the research purpose of each methodology is mentioned and the quantitative approach is used to describe or predict or to build and test theory.

The study carried out using the Deductive Method initially has defined a set of hypothesis based on models and theories. Therefore now it is the point where it connects with the questionnaire to test/asses the theory/models based on the hypothesis developed.

\subsubsection{Selection of a Research Method}

Creswell, (2003) recommends the research strategies which can be used to find answers to a research problem. They are namely: natural observation, test, experimental, survey and case study. The following is a table which is a brief discussion on the three types of research strategies available in order to analyze their feasibility for this research.

By using the findings of the above table, a surveys based on questionnaires were formed for data collection for this research while the collected date once analysed will be discussed with an Expert Panel to draw up conclusions and suggestions.

\subsection{Mapping of Research Questions Against the Hypothesis}

Prior to the execution of the survey, the questions designed are mapped against the hypothesis developed.

Table 4. Analysis of research Methods

\begin{tabular}{|c|c|}
\hline Research method & Analysis \\
\hline Experimental & $\begin{array}{c}\text { Experimental method helps you to determine the cause and effect and is considered to be a very powerful tool. However for } \\
\text { a situation where the Deductive Method is used, the Experimental Method will not fulfil the need of a better method. }\end{array}$ \\
\hline Survey & $\begin{array}{c}\text { Through the use of the Deductive Methods, the research is now ready with a defined set of hypothesis. Therefore the need } \\
\text { now will be to offer further analysis. This is where a survey method will fit in because of its ability to explain relationships } \\
\text { by gathering information. Surveys also offer unbiased sampling, a platform for standardization of measurements and } \\
\text { because of its ability to compliment existing data/facts from a secondary source. }\end{array}$ \\
\hline $\begin{array}{c}\text { Natural } \\
\text { observation }\end{array}$ & $\begin{array}{c}\text { Systematic observation of behaviour as and when it happens. As the study is not about behaviours this will not be a suitable } \\
\text { option for this research. }\end{array}$ \\
\hline Test & Tests behave on variables defined for an operation and will not be a sufficient method for this survey. \\
\hline Case Study & $\begin{array}{r}\text { Case studies come in two different variations (retrospective and proactive). However it will not be suitable as the study is } \\
\text { about innovation and its contribution for online presence. }\end{array}$ \\
\hline
\end{tabular}

Source: Authors own sources

Table 5. Mapping Research Questions against the Defined Hypothesis

\begin{tabular}{|c|c|}
\hline Hypothesis & Research question \\
\hline $\begin{array}{c}\text { Hypothesis 1: Innovation aspect for a hotel product is to concentrate } \\
\text { more on service innovation }\end{array}$ & $\begin{array}{c}\text { 19. It is far more easier for a hotel product to concentrate more on } \\
\text { service innovation than physical product innovations }\end{array}$ \\
\hline $\begin{array}{c}\text { Hypothesis 2: Most crucial aspect of new service innovation is } \\
\text { employees of a hotel }\end{array}$ & $\begin{array}{c}\text { 17. Employees cover the biggest share of service innovations (highest } \\
\text { contributor) }\end{array}$ \\
\hline $\begin{array}{c}\text { Hypothesis 3: The most crucial aspect for a hotel product is to } \\
\text { comprehend the 'need' to be innovative }\end{array}$ & 7. It is vital to understand the need to be innovative \\
\hline $\begin{array}{c}\text { Hypothesis 4: Organisational Culture is of highest importance to } \\
\text { achieve higher results in innovation. }\end{array}$ & $\begin{array}{c}\text { 10. Organizational culture must be defined to facilitate and encourage } \\
\text { innovations }\end{array}$ \\
\hline $\begin{array}{c}\text { Hypothesis 5: A hotel product needs to understand the types of } \\
\text { innovation which can be adopted. }\end{array}$ & $\begin{array}{c}\text { 16. A hotel product must understand the types of innovations they can } \\
\text { follow }\end{array}$ \\
\hline Hypothesis 6: A hotel product needs to gauge its level of innovation & 12. Hotel products must define their own level of innovation \\
\hline
\end{tabular}


Although there are 06 hypotheses mapped against 06 questions, the questionnaire covers a much wider viewpoint/data collection need out of the survey. The following survey questions are not directly associated with the listed hypothesis but were included due to its ability to compliment the process.

List of additional questions included in the survey to seek responses/views in support and to compliment the listed hypothesis as above:

6. Innovation is a manageable activity

8. Innovation is multi-dimensional even for a hotel product

9. Innovation has its own life cycle which is crucial to understand

11. Innovation has its own limitations

13. Innovation is related to both tangible and intangible assets

14. Innovations are not only technology oriented

15. Innovation helps to improve efficiency in many ways (e.g. reduce costs, improved competitiveness, etc.)

18. The presence of outstanding individuals can further help for service innovations

20. Being online is a must for a hotel product

21. Customers expects living 'experiences' from a hotel product

22. A hotel needs to have their own online strategy

23. Top-down management commitment is vital to achieve higher results using the online strategy

24. Technology innovations are also helpful for a hotel product

25 . Online reservation with instant confirmation is a very important tool for a hotel website

26. Hotel websites must offer up to date information

27. Hotel website should have a sufficient amount of images associated with text while more images are in demand

28. Hotels should have a consistent online presence beyond their own website

\subsection{Data Collection and Managing Responses}

\subsubsection{Web and E-mail}

In order to manage a higher success rate in response with high quality and error free, the web was primarily used to collect information while emails too were used to reach another segment of respondents. Where ever there was an error in data entry or a question was skipped, the respondent was contacted directly via phone or email to request his assistance to fill in the form completely. The survey request was forwarded to 215 pre-selected individuals and a response rate of $58 \%$ was observed.

A high response rate was achieved due to a follow up mechanisms executed simultaneously. In satisfying the defined hypothesis, more than a single variable was used. The data was then exported in to a MS-Excel file to evaluate the defined hypothesis discussed under the literature review.

\subsubsection{Focus Group Meeting}

The focus group meeting was concentrated and focused on to analyse the collected opinion feedback out of the survey. The objective of the Focus Group meeting was to further analyse and discuss on the hypothesis defined.

Due to cost measures the Focus Group was conducted through the online 'Skype' software with a high speed dedicated line to support the video broadcast. A total of 06 experts were requested to join the conversation. Selections of individuals were based on the criteria as follows:

- Geographical location: this was not seen as an advantage or a disadvantage but was used as an option to capture view of individuals from different geographies.

- Industry they represent: as the study was based on the hospitality industry the panel was selected to cover the hospitality and tourism sector.

- Years of acceptable industry experience: years of experience covering global brands.

- Knowledge, qualification and experience: considered individuals with the highest and also covering a strong intellectual base also.

- Communication and interpersonal skills: individuals with the ability to work with cross cultural discussion groups and respond comfortably.

The following is a list of individuals who contributed to this study:

- Brian Goonasekara - Canada:Brian has worked for some of the prestigious hotel brands such as the 'Hilton' and has years of experience in the hospitality industry in Asia, Europe and the Middle East.

Currently he works as a Lecturer at a prestigious Hospitality Teaching Academy in Canada.

- Linda Peddler - UK:Linda is from the Tourism cluster where she has over 20 years of experience handling more than 8 destinations covering over 400 hotels worldwide as a Contracting and Product Manager.

- Derrick Perera - Sri Lanka:Derrick has been with the prestigious 'Thomas Cook' tour operation based in Sri Lanka for over 30 years and has handled contracting and operational support with hotels in Sri Lanka and the Maldives.

- Althaf Mohomad Ali - Oman:Althaf is the Chief Operating Officer of one of the leading hotel chains in the Sultanate of Oman. The chain also manages a luxury desert camp in Oman as well. He has over 20 years of experience in hotels in Sri Lanka, Middle East and the Maldives.

- Wolfgang Heinsman - Germany:Wolfgang is the Head of Sales and Marketing for a prestigious, innovative budget chain of hotels in Germany and has over 25 years of experience as a hotelier.

- Gavin Godlieb - Australia:Gavin is an academic as well as a Hotel Manager of a Boutique hotel chain in Australia with over 15 years of experiences in tourism 
and hospitality. Gavin has over 6 years of experience with the world famous 'Taj' Group of hotels.

\subsection{Validity and Consistency of Data}

The research was based on a responded sample size of 125 individuals based in 17 different countries. The majority of the respondents are from Sri Lanka where the author is based at. Therefore there is a minor risk factor on 'data validity' as the responses do not necessarily offer a truly global perspective. Therefore the survey results would have offered a more global picture if there were sufficient responses received covering all continents. However in line with the research proposal, the survey has met the objective of reaching more than 02 continents. However the focus group managed to maintain a fair balance between all parameters concerned.

The author is from the hospitality industry and is based in Sri Lanka. The chance of more respondents being from the same industry would have been higher. However this was taken as a concern at the initial stage and responses from the individuals of the hospitality industry were controlled from the initial stages.

The survey targeted a group of individuals ranging from the ages of $18+$ with educational qualifications ranging from High School and above. This is a concern and is linked to the validity of data as certain response required a sound understanding of the term 'innovation'. This is linked to the misunderstanding of innovation as being creative. Harvard business review blog (2010) in its contributions specifically highlights this. Other references related to innovation in the references too have highlighted this. It can lead to certain respondents misunderstanding the question/questions. The term innovation is a subjective term which might also lead to individualistic definitions as well.

\section{Data Presentation and Analysis}

\subsection{Research Information}

The survey in addition to finding answers for the hypothesis developed collected a set of demographic information as well. This was considered to be a requirement to build cross links along with the rest of the results as well.

\subsection{Summary of Statistics - Initial/Demographic Variables}

Summary of the initial variables are mentioned below:
Table 6. Summary of Initial Survey Variables

\begin{tabular}{|c|c|c|c|}
\hline \multicolumn{2}{|c|}{ Variables } & $\begin{array}{l}\text { Frequency } \\
\text { distribution }\end{array}$ & $\begin{array}{c}\text { Distribution } \\
\text { as a } \%\end{array}$ \\
\hline \multirow{6}{*}{ Age group } & $18-24$ & 15 & $12.00 \%$ \\
\hline & $25-31$ & 30 & $24.00 \%$ \\
\hline & $32-38$ & 28 & $22.40 \%$ \\
\hline & $39-45$ & 19 & $15.20 \%$ \\
\hline & $46-52$ & 23 & $18.40 \%$ \\
\hline & 52 up & 10 & $8.00 \%$ \\
\hline \multirow{17}{*}{$\begin{array}{l}\text { Country of } \\
\text { nationality }\end{array}$} & Australia & 8 & $6.40 \%$ \\
\hline & Bangladesh & 1 & $0.80 \%$ \\
\hline & Belize & 1 & $0.80 \%$ \\
\hline & Canada & 7 & $5.60 \%$ \\
\hline & China & 2 & $1.60 \%$ \\
\hline & France & 6 & $4.80 \%$ \\
\hline & Germany & 2 & $1.60 \%$ \\
\hline & India & 11 & $8.80 \%$ \\
\hline & Japan & 1 & $0.80 \%$ \\
\hline & Maldives & 10 & $8.00 \%$ \\
\hline & New Zealand & 7 & $5.60 \%$ \\
\hline & Oman & 8 & $6.40 \%$ \\
\hline & Saudi Arabia & 1 & $0.80 \%$ \\
\hline & Singapore & 6 & $4.80 \%$ \\
\hline & Sri Lanka & 24 & $19.20 \%$ \\
\hline & $\begin{array}{l}\text { United Kingdom of } \\
\text { Great Britain and } \\
\text { Northern Ireland }\end{array}$ & 12 & $9.60 \%$ \\
\hline & $\begin{array}{c}\text { United States of } \\
\text { America }\end{array}$ & 18 & $14.40 \%$ \\
\hline \multirow{7}{*}{$\begin{array}{l}\text { Educational } \\
\text { background }\end{array}$} & Elementary & 0 & $0.00 \%$ \\
\hline & High School & 15 & $12.00 \%$ \\
\hline & Some Diploma & 18 & $14.40 \%$ \\
\hline & Bachelors & 38 & $30.40 \%$ \\
\hline & Masters & 26 & $20.80 \%$ \\
\hline & Doctorate & 4 & $3.20 \%$ \\
\hline & $\begin{array}{l}\text { Professional } \\
\text { qualification }\end{array}$ & 24 & $19.20 \%$ \\
\hline \multirow{16}{*}{$\begin{array}{l}\text { Industry / } \\
\text { employment } \\
\text { sector }\end{array}$} & Self employed & 9 & $7.41 \%$ \\
\hline & Trading & 9 & $7.41 \%$ \\
\hline & Engineering & 9 & $7.41 \%$ \\
\hline & $\begin{array}{c}\text { Hospitality \& } \\
\text { Tourism }\end{array}$ & 5 & $3.70 \%$ \\
\hline & Academic & 5 & $3.70 \%$ \\
\hline & Plantation & 0 & $0.00 \%$ \\
\hline & Advertising & 8 & $7.41 \%$ \\
\hline & $\begin{array}{c}\text { Communications \& } \\
\text { IT }\end{array}$ & 35 & $29.63 \%$ \\
\hline & Textile \& Apparel & 0 & $0.00 \%$ \\
\hline & Banking \& Finance & 25 & $18.52 \%$ \\
\hline & Shipping \& Cargo & 0 & $0.00 \%$ \\
\hline & $\begin{array}{l}\text { Medicine \& } \\
\text { Healthcare }\end{array}$ & 10 & $7.41 \%$ \\
\hline & Legal & 0 & $0.00 \%$ \\
\hline & Defence & 0 & $0.00 \%$ \\
\hline & Government & 5 & $3.70 \%$ \\
\hline & Not employed & 5 & $3.70 \%$ \\
\hline
\end{tabular}


A majority of respondents are in the $25-31$ age groups and are based in Sri Lanka with a minimum of a Bachelor's Degree and belong to the communications and IT sector.

A majority of them being Bachelor's Degree qualifications holders offers an advantage for the survey as most of them are knowledgeable. Therefore some of the concerns which were mentioned in the data validations become very low as a majority of them have a minimum of a Bachelor's Degree or a professional qualification.

It was an achievement to be able to capture the second highest set of respondents from the United States in order to create a balance between a developing country such as Sri Lanka and a technologically advanced developed economy such as the USA. This leads to the achievement of a quality set of responses with a good variety of viewpoints being collected. The UK \& Ireland were the $3^{\text {rd }}$ highest segment and this combined with the segment from the USA, can be considered as the biggest geographic segment.

The author believes it is to the advantage that the majority of the respondents were not from the 'hospitality/tourism' sector (employed). As they can be biased towards their own believes and the industry. The opinions mentioned herein can be categorized as comparatively unbiased.

\subsection{Detailed Analysis: Questionnaire}

\subsubsection{Question 6:Innovation is a Manageable Activity}

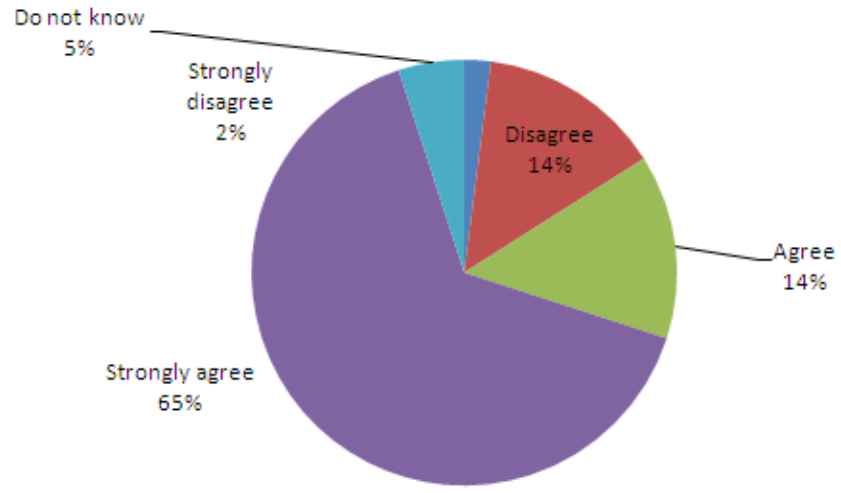

The majority of the respondents believed and accepted that the innovation needs to be managed. In this scenario very few disagreed with the statement. $65 \%$ of the respondents strongly agreed with this statement while strongly agree and agree which is accepted as positive acceptances accounted to $96 \%$ from the total sample size and which is a great majority.

\subsubsection{Question 7: It is Vital to Understand the Need to be Innovative}

\section{Hypothesis Tested}

- Hypothesis 3: The crucial aspect will be to understand the need of being innovative is to be ahead of the rest

The respondents very strongly confirmed the importance of knowing the need to be innovative.

This is the highest. Out of the $65 \%$ who accepted that the innovation has to be managed, $100 \%$ of them strongly agreed that an organization should understand the need to be innovative.

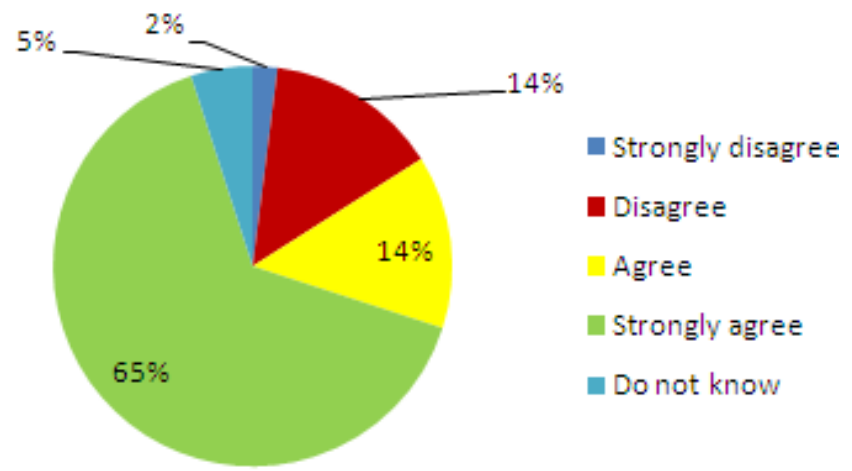

4.3.3. Question 8: Innovation is a Multi-dimensional Event for a Hotel Product

The weight in favor of this question was not strong as the strongly agree segment was only 57\%. However if the positive responses are considered together, it covers an impressive share of $85 \%$ in favor of the statement. It was interesting to note that of the 92 individuals who previously agreed that an organization needs to understand the need for innovation only $87 \%$ contributed to strongly agree on this question. Negative responses covered $15 \%$ of the share of the responses.

4.3.4. Question 9: Innovation has its Own Life Cycle Which is Crucial to Understand

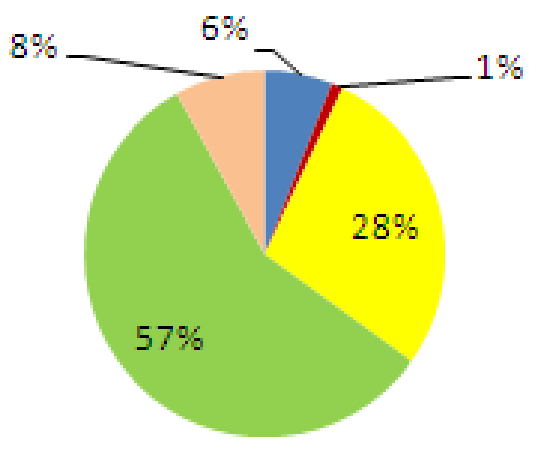

Strongly disagree

Disagree

Agree

Strongly agree

At this stage $69 \%$ of the respondents agreed that innovation has its own life cycle. However, only $18 \%$ of the respondents strongly agreed to this statement. A majority of $88 \%$ responded in favour of this statement.

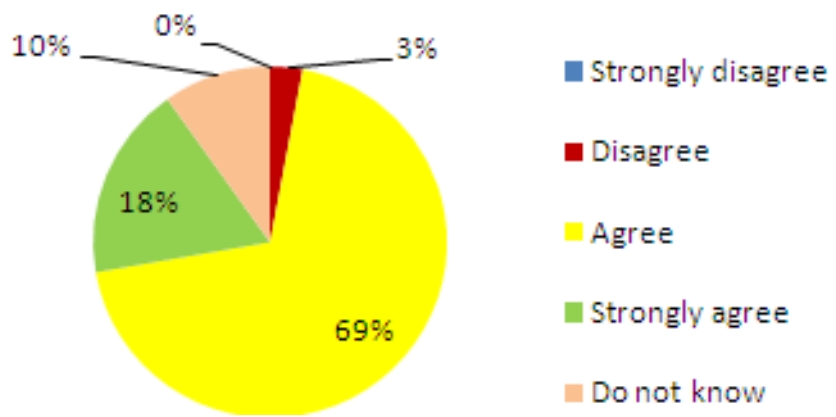

4.3.5. Question 10: Organizational Culture Must be Defined 
to Facilitate and Encourage Innovations

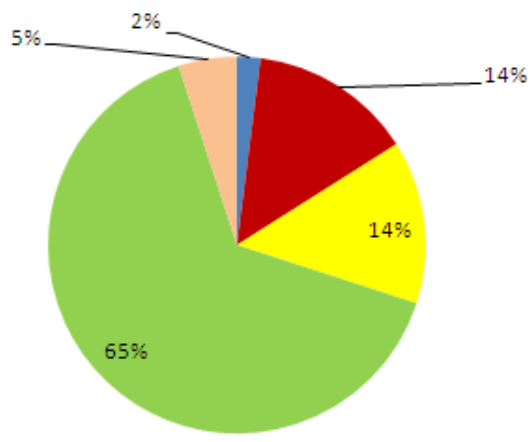

Hypothesis Tested
- Hypothesis 4: To achieve higher results in innovation an organizational culture should be defined and groomed towards it.

A total of $75 \%$ of the respondents strongly agreed to this hypothesis which was tested. The positive answer share of this question was $97 \%$. This clearly records that the organizational culture has a strong link with innovation and the culture needs to be defined finely while grooming was accepted as a priority.

\subsubsection{Question 17: Employees Cover the Biggest Share of} Service Innovations (Highest Contributor)Question 18: The Presence of Outstanding Individuals can Further Help for Service Innovations.

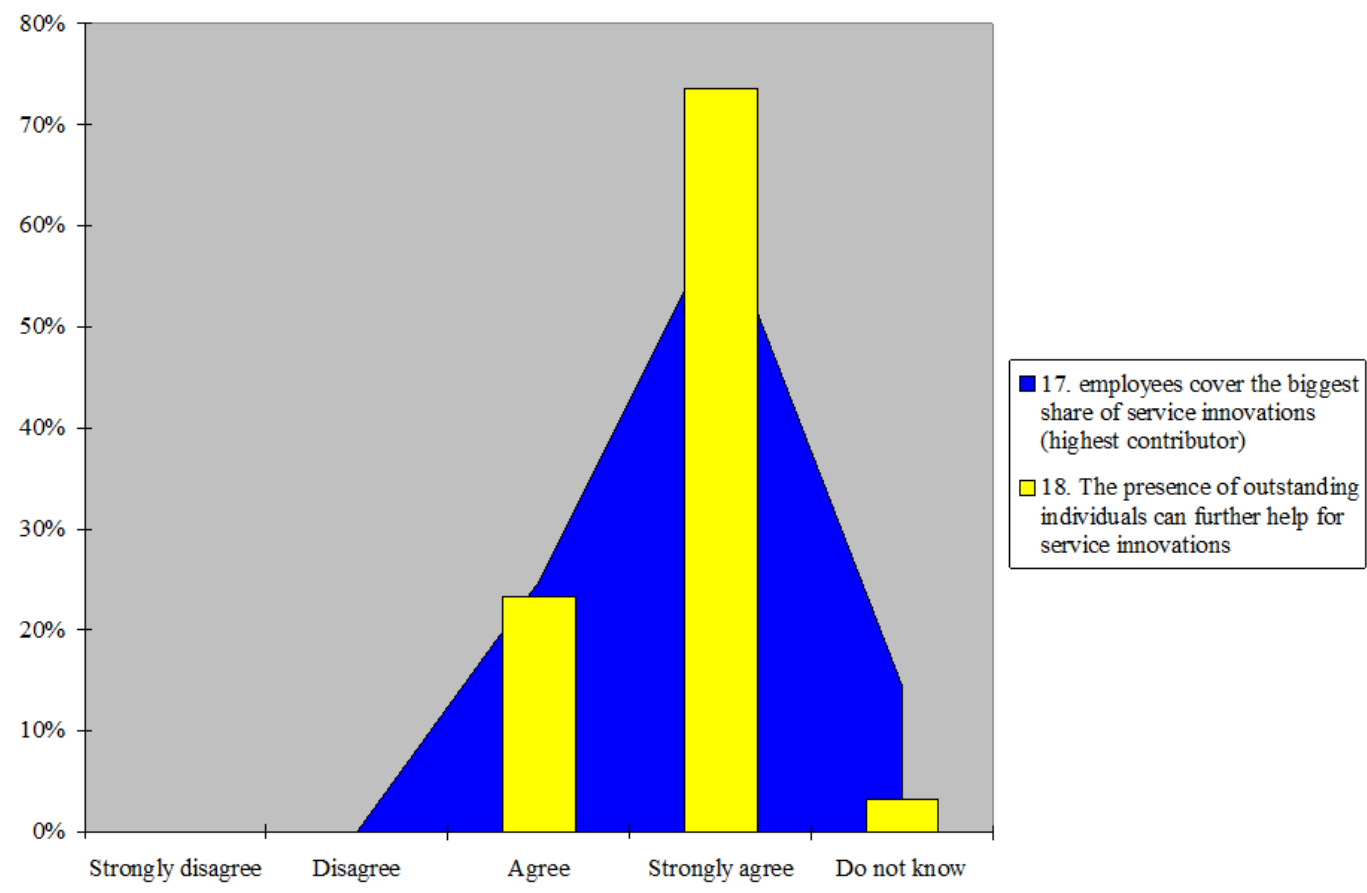

\section{Hypothesis Tested}

- Hypothesis 2 (question - 17): Most crucial aspect of new service innovation is employees of a hotel

The above hypothesis tested had strong links as both questions refer to employees of a hotel and how an outstanding individual can contribute to the success of innovation. The results show a strong link between the two elements as their share of responses is equally higher. $86 \%$ of the positive responses agreed that there is a strong justification that employees play a larger share of innovation and $97 \%$ of them responded positively on the importance of outstanding individuals to achieve excellence in innovation.

4.3.7. Question 11: Innovation has its Own Limitations

Table 7. Survey results for question 1

\begin{tabular}{|c|c|c|c|c|c|}
\hline \multirow{2}{*}{$\begin{array}{c}\text { Question } \\
\text { No. }\end{array}$} & \multicolumn{5}{|c|}{ Responses } \\
\cline { 2 - 6 } & $\begin{array}{c}\text { Strongly } \\
\text { disagree }\end{array}$ & Disagree & Agree & Strongly agree & Do not know \\
\hline 11 & $2 \%$ & $14 \%$ & $14 \%$ & $65 \%$ & $5 \%$ \\
\hline
\end{tabular}

$65 \%$ of the respondents strongly agreed on this question offering a strong justification for this hypothesis. Once the positive responses are combined the justification becomes even stronger with a $79 \%$ higher majority.

\subsubsection{Question 12: Hotel Products must Define Their Own Level of Innovation.}

Question 16: A Hotel Product must Understand the Types of Innovations they can follow 


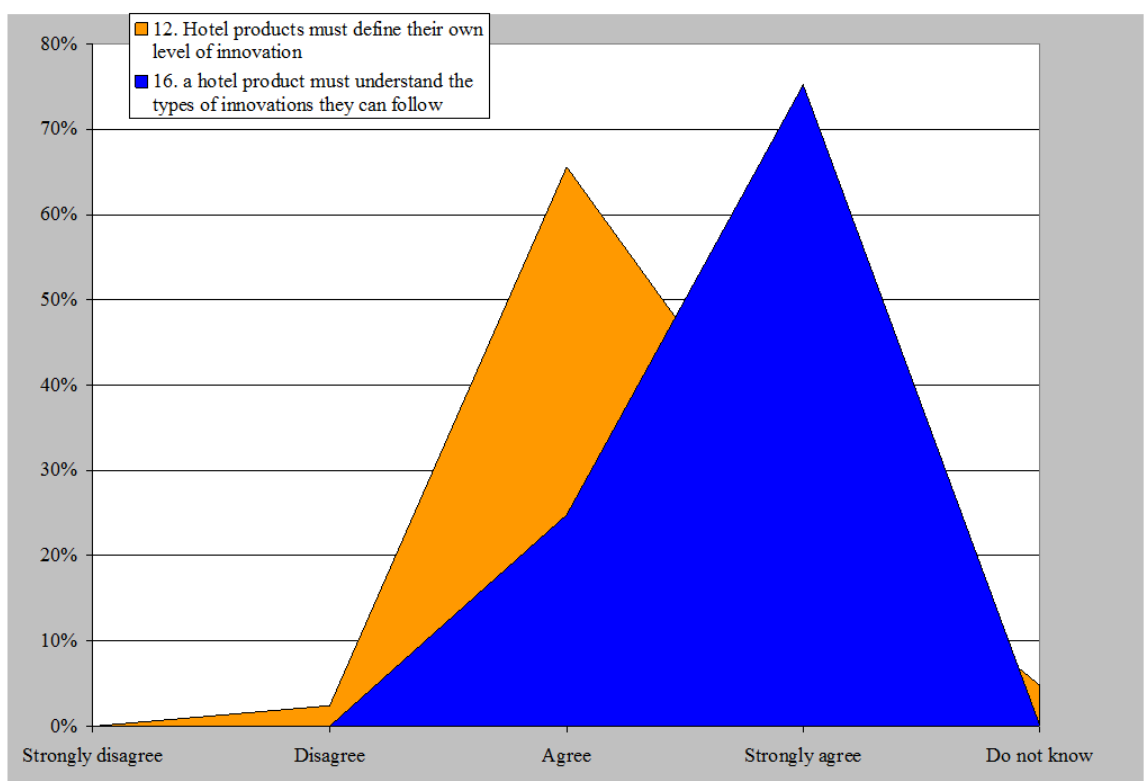

\section{Hypothesis Tested}

- Hypothesis 5: A hotel product needs to understand the types of innovation which can be adopted.

- Hypothesis 6: A hotel product needs to gauge its level of innovation

A majority of positive responses of $93 \%$ agreed that a hotel product should define a level of innovation for itself while $100 \%$ of the responses stood positively that a hotel should understand the types of innovations it should adopt. This highlights the fact that a hotel not only should practice innovation but also needs to be managed. This also connects with question 6/hypothesis -3 which highlights the importance of managing innovation and where the above is described as an integral part of innovation.

\subsubsection{Question 13: Innovation is Related to Both Tangible and Intangible Assets}

Question 14: Innovations are not only Technology Oriented

Question 15: Innovation Helps to Improve Efficiency in Many Ways (E.G. Reduce Costs, Improve Competitiveness, Etc.)

Question 19: It is Far Easier for a Hotel Product to Concentrate More on Service Innovation than Physical Product Innovations

Question 24: Technology Innovations Too are Helpful for a Hotel Product

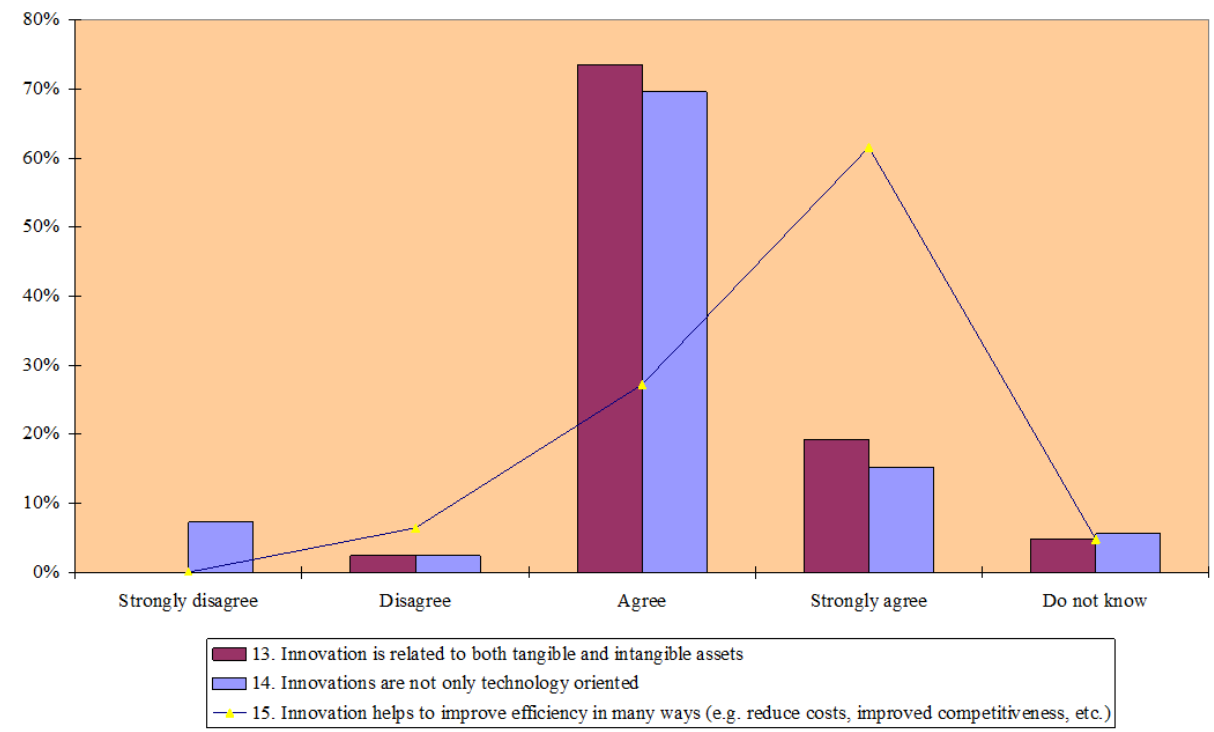


- Hypothesis 1: Innovation aspect for a hotel product is to concentrate more on service innovation

The above chart analyses questions $-13,14 \& 15$ while the table below which is used along with them is included in the table below.

These 03 questions combined together is a fine analysis of how innovation affects an organization (hotel product). Respondents not only accept $93 \%$ positively that innovation is linked to tangible as well as for intangible assets but also $85 \%$ acceptance that all innovations are not technology related. However this doesn't iron out the fact that 'technology innovations too can contribute for a hotel product and is accepted with a $89 \%$ positive responses (see table below) by the respondents. This also connects with question no: 19 where 'service innovation' has been identified as a key strategy for a hotel product. The table below represents the individual responses received for all questions while it shows of a very strong $90 \%$ positive response in favour of concentrating more on innovation is services in comparison to a physical product as justified in the literature review.

Table 8. Survey results tables for questions $13,14,15,19,24$

\begin{tabular}{|c|c|c|c|c|c|}
\hline \multirow{2}{*}{$\begin{array}{c}\text { Question } \\
\text { No. }\end{array}$} & \multicolumn{5}{|c|}{ Responses } \\
\cline { 2 - 6 } & Strongly disagree & Disagree & Agree & $\begin{array}{c}\text { Strongly } \\
\text { agree }\end{array}$ & Do not know \\
\hline 13 & $0 \%$ & $2 \%$ & $74 \%$ & $19 \%$ & $5 \%$ \\
\hline 14 & $7 \%$ & $2 \%$ & $70 \%$ & $15 \%$ & $6 \%$ \\
\hline 15 & $0 \%$ & $6 \%$ & $27 \%$ & $62 \%$ & $5 \%$ \\
\hline 19 & $0 \%$ & $4 \%$ & $16 \%$ & $74 \%$ & $6 \%$ \\
\hline 24 & $0 \%$ & $0 \%$ & $19 \%$ & $70 \%$ & $11 \%$ \\
\hline
\end{tabular}

Additionally question 15 which tests hypothesis 8 very strongly accepts that innovation can bring in a lot of values to an organization. This also connects with question 8 testing the $4^{\text {th }}$ hypothesis defined that innovation is multi-dimensional.

4.3.10. Question 21: Customers Expect Living 'Experiences’ from a Hotel

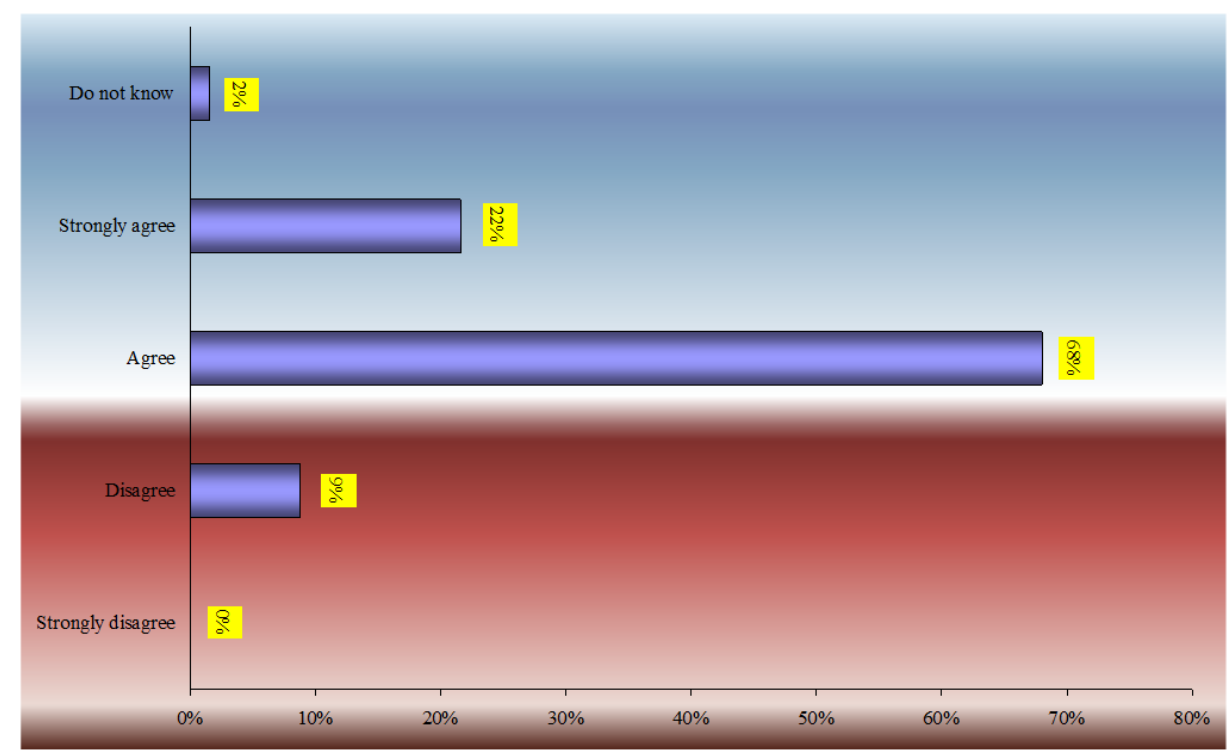

This is one key aspect which was critically analyzed in the Literature Review section. The respondents of the survey agreed on this statement and the total share of positive responses were high as $90 \%$. This proves as a general statement. However the author believes that an 'experience' based hotel concepts varies based on certain factors such as star classification, location, number of rooms, etc.

\subsubsection{Question 20: Being Online is a Must for a Hotel Product}

Question 22: A Hotel needs to have Their Own Online Strategy

Question 23: Top-Down Management Commitment is Vital to Achieve Higher Results Using The Online Strategy 


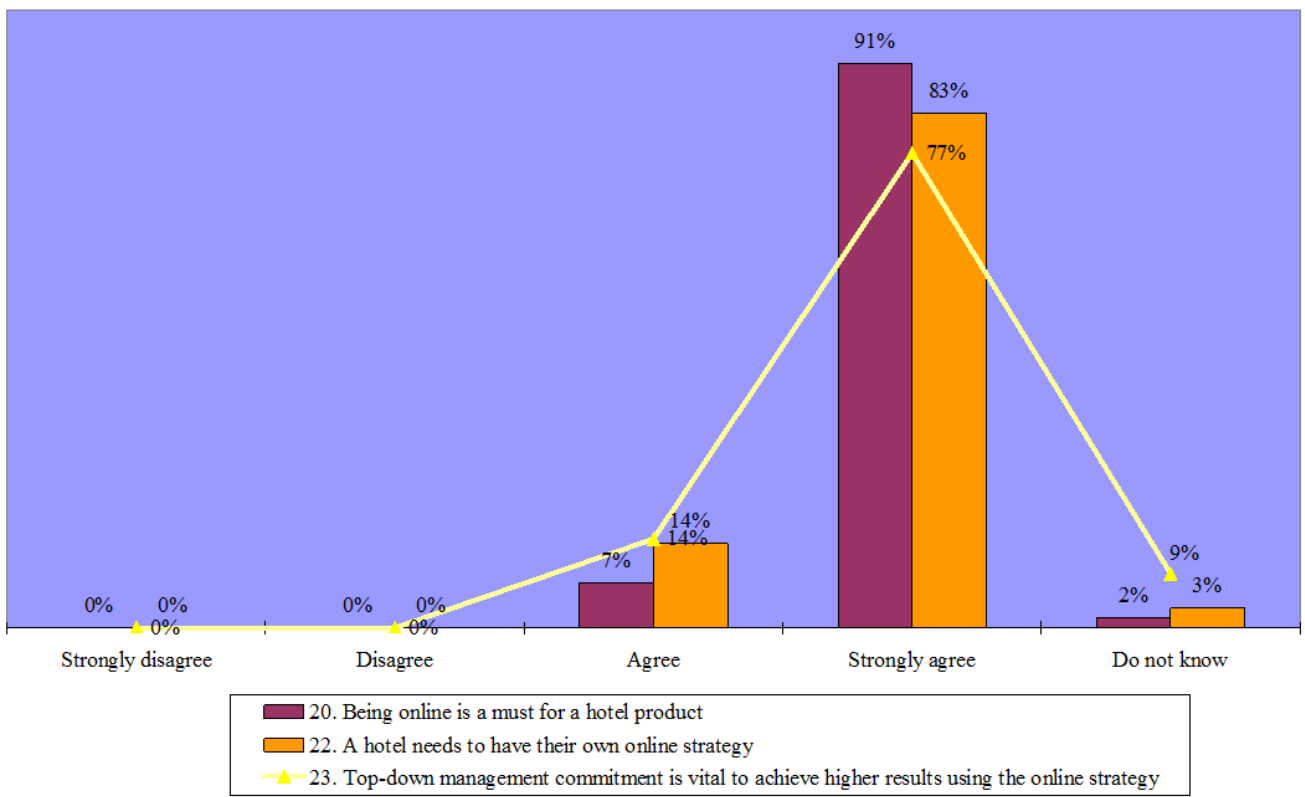

At this stage the objective was to measure the responses on the importance of online presence of a hotel and its strategy. Considering the 03 questions, they are on a pattern where the basics of the online presence starting from understanding the importance of a hotel being online with a good strategy in place to the level of identifying the significance of the top-down commitment to achieve superior online presence.

Respondents 'strongly agreed' with a high rating of $91 \%$ and a total positive rating of $98 \%$ that being online is a must for a hotel product. They also confirmed that a hotel should have a clear online strategy with provision for continuous improvement by $83 \%$ positive responses. $91 \%$ of them agreed strongly that a hotel to achieve online presence, top-down management commitment is a must. Therefore the respondents agree that online presence is a must and a good online strategy will be of no use if the management commitment from top to bottom is not present.

\subsubsection{Question 25: Online Reservation with Instant Confirmation is a Very Important Tool for a Hotel Website}

Question 26: Hotel Websites Must Offer Up to Date Information

Question 27: Hotel Website Should Have a Sufficient Amount of Images Associated with Text with More Images

Table 9. Survey results tables for questions 25, 26, 27

\begin{tabular}{|c|c|c|c|c|c|}
\hline \multirow{2}{*}{ Question No. } & \multicolumn{5}{|c|}{ Responses } \\
\cline { 2 - 6 } & $\begin{array}{c}\text { Strongly } \\
\text { disagree }\end{array}$ & Disagree & Agree & Strongly agree & $\begin{array}{c}\text { Do not } \\
\text { know }\end{array}$ \\
\hline 25 & $0 \%$ & $0 \%$ & $9 \%$ & $90 \%$ & $2 \%$ \\
\hline 26 & $0 \%$ & $0 \%$ & $9 \%$ & $90 \%$ & $2 \%$ \\
\hline 27 & $0 \%$ & $0 \%$ & $9 \%$ & $90 \%$ & $2 \%$ \\
\hline
\end{tabular}

The above 03 questions were included to satisfy 03 of the key characteristics of a hotel website: the online reservations system, images and text. This is one crucial aspect for a hotel where too many images and complicated text layouts and structures contribute negatively for a superior online presence. A higher amount of images not also makes the downloading speed also slow it also makes the time spent to access a page higher. In this scenario images and text/information comes first while up on convincing the clients to use the product on same. There should be a quick link to secure the business through an online real time reservation system with instant confirmation. This is a very contributory aspect for a hotel where the decision making can change because of the key things as above. It was surprisingly noted that all respondents, respond in the same way to all 03 questions.

$99 \%$ positive responses received conforming that the hotel booking engines should be real time while the same amount of share (99\%) was offered in favour of question 26 and 27 . The ideal option is to have up to date text with a simple easy to read layout and a good collection of images optimized for faster download while additional images on demand via the same website. 


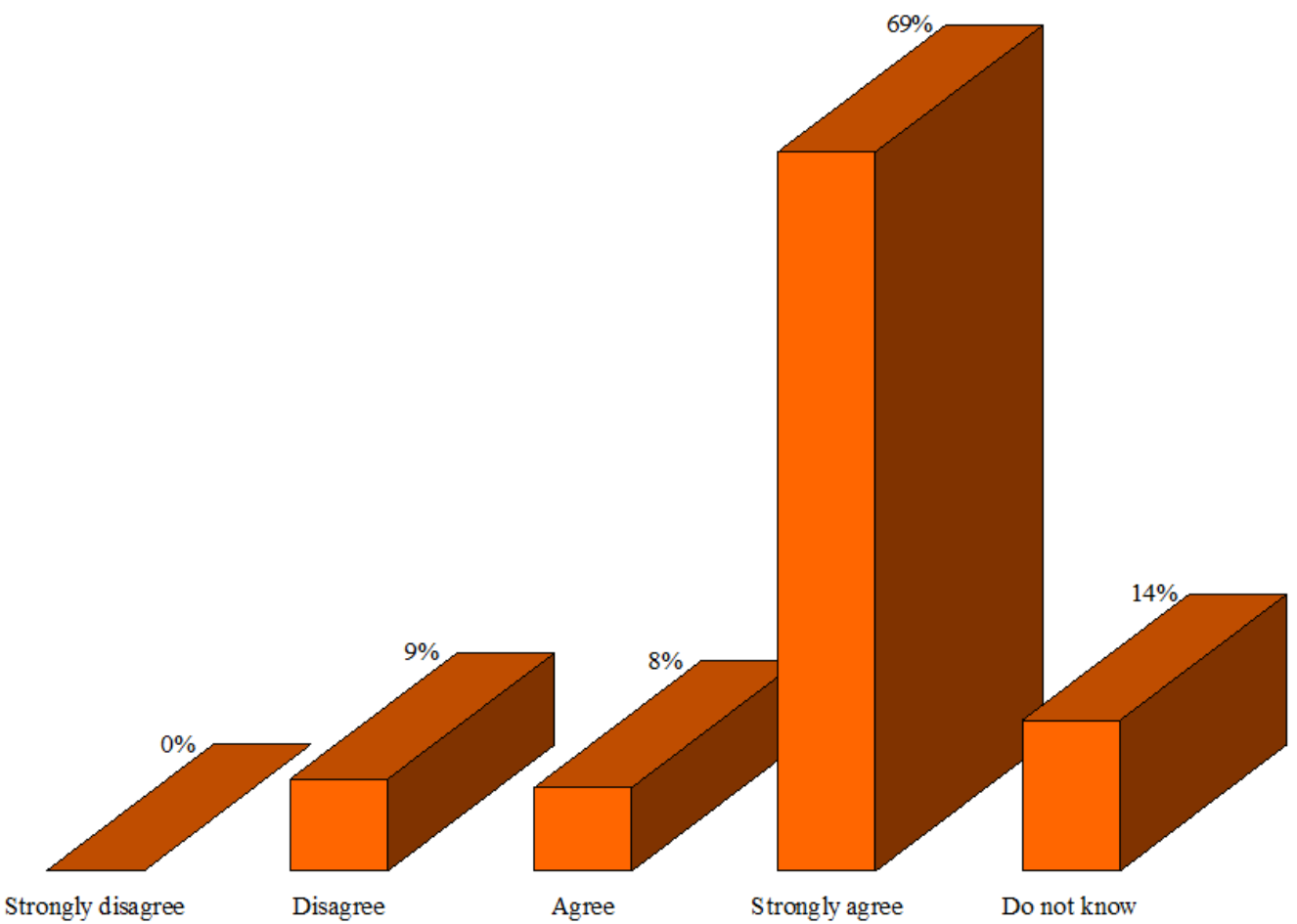

Table 10. Detailed analysis: Focus Group outcome

\begin{tabular}{|c|c|}
\hline Hypothesis & Respondents view point in brief \\
\hline $\begin{array}{l}\text { Hypothesis 1: Innovation } \\
\text { aspect for a hotel product is } \\
\text { to concentrate more on } \\
\text { service innovation } \\
\text { Hypothesis 5: A hotel } \\
\text { product needs to understand } \\
\text { the types of innovation } \\
\text { which can be adopted. } \\
\text { Hypothesis 6: A hotel } \\
\text { product needs to gauge its } \\
\text { level of innovation }\end{array}$ & $\begin{array}{l}\text { The group identified 'Hypothesis - } 1 \text { (the question tossed to them in relation to same) this as a significant } \\
\text { option. } \\
\text { Primarily due to limitations of physical product innovation. } \\
\text { Cost of innovation and ease of copying by competitors was also seen as disadvantages over service } \\
\text { innovation. } \\
\text { However the group highlighted the fact that the physical product too will have to have its own distinct } \\
\text { innovative design also. } \\
\text { The group further highlighted on the importance of a hotel testing or seeking suitable options to evaluate } \\
\text { innovations and approaches for innovation prior to implementation also. } \\
\text { The group pointed out the importance of strategising the innovation with types and levels of innovations } \\
\text { defined. The group accepted that a hotel might have to consider different types and levels of innovation } \\
\text { for a hotel product and use across as relevant. } \\
\text { The fundamental concern was that innovation should add value to an operation, process or procedures } \\
\text { and not contribute negatively. At this point one of the respondents share his/her views on the initial } \\
\text { computerisation of a hotel, where guests were harassed with a load of information to fill in the check in } \\
\text { form. }\end{array}$ \\
\hline $\begin{array}{l}\text { Hypothesis 2: Most crucial } \\
\text { aspect of new service } \\
\text { innovation is employees of a } \\
\text { hotel } \\
\text { Hypothesis } 4 \text { : } \\
\text { Organisational Culture is of } \\
\text { highest importance to } \\
\text { achieve higher results in } \\
\text { innovation. }\end{array}$ & $\begin{array}{l}\text { Although there are two hypotheses covering the employees and the culture separately, the expert panel } \\
\text { positioned them together. } \\
\text { One key concern the group believed is that there is no purpose of introducing capable, innovative } \\
\text { employees to a system if they are not cushioned with the rights organisational culture. } \\
\text { The group also had concerns over building organisational culture over a multi-cultural, multi-national } \\
\text { environment. One of the group members shared an experience of a hotel based in Asia and how the } \\
\text { employees negatively reacted to a 'better culture' which was trying to be introduced by a Westerner. } \\
\text { The group together agreed that the organisational culture of a hotel provides the key environment for } \\
\text { employees to be innovative. } \\
\text { They also agreed that individual (especially outstanding employees) can contribute immensely to service } \\
\text { innovation especially in a hotel. }\end{array}$ \\
\hline $\begin{array}{l}\text { Hypothesis } 3 \text { : The most } \\
\text { crucial aspect for a hotel } \\
\text { product is to comprehend the } \\
\text { 'need' to be innovative }\end{array}$ & $\begin{array}{l}\text { When this question was tossed (indirectly) to the panel they had } 02 \text { different views on same. } \\
\text { The first view was - analysing against some of the theoretical background, a hotel product from its } \\
\text { inception should continuously seek possible avenues to excellence in innovation. } \\
\text { The second viewpoint is that the need must be associated with the target customer expectations } \\
\text { (associating this with hypothesis - 1). } \\
\text { Therefore the group agreed that the need triggered should not hinder the needs of the potential customer. }\end{array}$ \\
\hline
\end{tabular}


This was perceived as a myth that hotels should only concentrate on their own website. In fact this connects with the online strategy which is covered previously as well and is an integral part of same. One cannot limit a hotel website to its own website as that it would limit expanding through channels. Therefore multiple websites offer the choice of expanding the online presence and a platform to be better available. However the question covers a deeper range where the online strategy of a hotel is associated with $3^{\text {rd }}$ party websites which also maintains consistency. Customers look for one-stop shop solutions and often build relationships/bonds with websites also. Therefore it is of much importance that a hotel should not only limit its online availability to its own website. Respondents decided to offer a higher positive share of $77 \%$ making it very important.

\subsection{Detailed Analysis: Focus Group}

The focus group meeting was directed based on hypothesis defined in the earlier chapter. The discussion lasted a total of 106 minutes, 16 minutes over and above the planned timing. This is justifiable with the concerns such as the medium being used and the time differences of different countries selected.

The discussion combined with hotel managers/service providers and users had a bundle of information to share on their experiences. The researcher felt that the group satisfied greater number of requirements of the group including active believe in 'innovation' by most of them.

\section{Conclusions and Recommendations}

\subsection{Conclusion}

In a rapidly changing world with increasing competition a hotel product is expected to be innovative in its own way. Therefore the primary objective of this research was to identify the aspects of innovation and its contribution for a hotel product. The research was also expected to analyze how innovation can help to achieve online presence. Based on the survey outcomes, the follow-up face to face interviews and some of the previous research being carried out on same the conclusions out of this research can be documented as per the below.

\subsubsection{Innovation and its Significance for a Hotel Product}

Innovation was identified to be an inbuilt component of a hotel product for offering greater competitiveness for a hotel. This can be in two aspects where tangible innovation and intangible innovation which brings in optimistic results for a hotel. Tangible innovation was found to be more with the physical aspect while intangible innovation was more on the services aspect of a hotel. The survey found that there can be limitations developing and working on physical product innovation while service innovation was recommended to be a better alternative. This was primarily due to the fact that the survey concluded that most of the hotel services can be easily substitutable. Therefore service innovation was accepted as the best alternative option. The technological innovations too were accepted as a part of an innovation based culture of a hotel however was never accepted as the only option. The most important aspect for a hotel is to identify that there is a need to be innovative to stand ahead the rest. Innovation is not only to improve the competitive position of same but also help a hotel to achieve a bundle of return. For example: reduced costs, improved efficiency, shorter response time, etc.

The research critically analyzed the factors which can influence innovative service delivery such as the following:

- Innovation needs to be embedded into an organizational culture

- Organizational culture needs to be developed and groomed on a continuous basis

- The key to a better organizational culture is to develop a team which believes in it and therefore individuals form the biggest portion of an effective culture.

- In addition, extraordinary individuals was found to be the biggest asset for an organization which believes in innovation and an innovation based culture for a hotel

- An innovation strategy would definitely help a hotel product to perform better

\subsubsection{How Innovation can Help to Achieve Superior Online} Presence

The analysis very strongly highlighted the fact that a hotel should have an online presence. The analysis went on to clear a myth that online presence is only related to the hotel website. The importance of retaining a customer online too was discussed and analyzed. The factors which can assist to retain a customer too were identified briefly. However in a rapidly changing environment achieving superior online presence may seem a comparatively easier task. The most crucial task would be sustain and continue the achieved results for the future.

The research critically analyzed the factors related to innovation and online presence and how innovation can help to enhance the online presence:

- A hotel product must have its own online strategy

- This should be a vision derived from the top management and shared among rest of the levels.

- Online strategy should cover the hotel website as well as online presence across the cyber space.

- A hotel website must comply with the right amount of images and additionally on demand while text / information should be up to date.

- Online presence is a customer centric operation and therefore the strategy must comply with the needs of the customer.

\subsection{Recommendations}

Although the research covered a fairly a larger range with regards to innovations and its associations for online 
presence; it has to be understood that the term innovation is a very subjective word. Therefore one such recommendation for a hotel product is to use benchmarking and related methodologies to assess its competitive position. This might help to understand competitive positioning against a world class product.

The conclusions of this survey are based on a more generalized research approach where the conclusions are documented to satisfy a macro environment. However it is important to understand that individual hotels products are unique and one has to be aware of this. A strong understanding of the individual characteristics of a hotel is a must prior to seeking avenue for innovation.

Staff training and development covers an integral aspect of developing an organizational culture. Strong Human Resources practices help an organization to grow along with its own staff and develop a better organizational culture. Organizational culture is not only about grooming staff to be innovative but covers a variety of other aspects which are required for a smooth functioning of a hotel. Innovation should be one aspect embedded to organizational culture.

Innovations related to costs as well and which needs to asses on its feasibility prior to its implementation. Also a suitable model must be used to evaluate a feasibility of an innovation and its appropriateness for a hotel product. This is vital as all innovations should compliment the overall vision and objectives of the hotel. A good innovation must be tested against the operational model of the hotel as well as the customer expectations and competitiveness.

No perfect model exists for a website. Creativity is a key concern where creative elements must satisfy the needs of a potential customer. Therefore a hotel must have its own strategy for its online presence and which should be a customer centric choice in line with the overall vision and objectives. Certain technologies might not work in the best way for a hotel and must be analyzed prior to actual use.

Innovation must be treated as an ongoing process in all ways. It is vital to be aware of the limitations such as barriers to innovation as barriers can hinder the outcome of an innovation.

\subsection{Implications and Further Research}

The survey covered only 125 respondents covering 17 countries. A majority of them were from Sri Lanka and this may be argued not as a sufficient sample to decide on a macro picture. Even with a higher cost factor a boarder survey would have helped the research.

The profiling of the respondents was controlled by the majority of them being in the IT/communications sector. It would have been a better option to expend same to a more balanced approach with various industries covered as a best example of another industry may be of use to a hotel as well.

The survey was conducted using a web based and email based mediums. It is accepted that the survey at times may have implications of it being very technical as a better understanding of theories would have required answering the questions. However as a majority of them being educated at a Bachelor's Degree/professional qualification level or above it helped the survey to find better results/responses. If not for this there would have been chances of survey responses being not valid. A series of focus group meetings would have complimented the process but is a costly exercise as the respondents must represent more than one country of geographical region.

Almost all respondents run through busy schedules in their daily life. This was a major obstacle to achieve while collecting date for the survey as well as requesting and coordinating a web based focus group meeting with 06 key professionals in 06 different time zones.

\section{REFERENCES}

[1] Carroll, B. and Siguaw, J. (2003) The evolution of electronic distribution: effects on hotels and intermediaries. Cornell hotel and restaurant administration quarterly, 44(38), pp. $38-50$

[2] Creswell, J.W. (1998). Qualitative inquiry and research design: choosing among five traditions. CA: Sage.

[3] Creswell, J.W. (2003). Research design. Qualitative, quantitative and mixed methods approaches. CA: Sage.

[4] Cooper, D.R. and Schindler, P. S (2008). Business research methods. 9th ed. New Delhi: Mc Graw-Hill.

[5] Cook, S. (1995) Practical benchmarking. 1st ed., UK: Kogan Page

[6] Colombia university press (2009) Online encyclopaedia, Available from:

http://education.yahoo.com/reference/encyclopedia

[Accessed: 10th June 2010]

[7] Dobni, C B. (2008) Measuring innovation culture in Organizations: The developments of a generalized innovation culture construct using exploratory factor analysis. European Journal of Innovation Management, 11(4), pp. 539-559

[8] Drucker, P. (2008) The essential drucker. 1st ed., New York: HarperCollins

[9] Drucker, P. E. (2007) Classic drucker collection edition., UK: Butterworth-Heinemann

[10] Gorman, T. (2010) Innovation. 1st ed., USA: Adams Business

[11] Gazzoli, G., Kim, W. G. and Palakurthi, R. (2008) Online distribution strategies and competition: are the global hotel companies getting it right?. International journal of contemporary hospitality management, 20(4), pp. 375-387

[12] Harvard business review - bloggs (2010), Innovation is not creativity, Harvard Business liable Review, US. Available from:

http://blogs.hbr.org/govindarajan/2010/08/innovation-is-notcreativity.html [Accessed: 14th March 2011]

[13] Hoshi-Japan (2011) The world's oldest hotel, Japan. Available from: http://www.ho-shi.co.jp [Accessed: 7th Jan 2011] 
[14] Krippendorff, K. (2010) The way of innovation. 1st ed., USA: Platinum Press

[15] Kotler, P. and Keller, K.L. (2006) Marketing Management 12th ed. Hemel Hempstead; Prentice Hall

[16] Namasivayam, K., Enz, C. A. and Siguaw, J. A (2000) How wired are we? Cornell hotel and restaurant administration quarterly, 41(6), pp. $40-48$

[17] Ninemsn (2011), The worlds oldest hotel, MSN, US. Available from http://getaway.ninemsn.com.au/fsasia/japan/146373/hoshi-1 51-the-worlds-oldest-hotel [Accessed: 7th Jan 2011]

[18] O'Connor, P. and Frew, A. J. (2002) The future of hotel electronic distribution: expert and industry perspectives. Cornell hotel and restaurant administration quarterly, 43(3), pp. $33-45$

[19] OECD and Eurostat (2010), Oslo Manual - Guidelines for collecting and Interpreting Innovation data, OECD, Paris. Available from: http://www.oecd.org/document/22/0,3343,e n $41462537 \quad 4145485644979734 \quad 1 \quad 1 \quad 1 \quad 1,00 . h t m l$ [Āccessed: $1 \overline{2}$ th June 2010$]$

[20] Ottenbacher, M., and Gnoth, J.(2005) How to develop successful hospitality innovation. Cornell hotel and restaurant administration quarterly, 46(2), pp. 205-222

[21] Painter A., (2007) Opening and operating bed and breakfast in the 21 st century. 1 st ed. USA: Bed and breakfast inn keepers association

[22] Porter, M. \& Stern, S. (2001) Innovation: location matters. MIT Sloan Management Review: The Institute for Strategy and Competitiveness, 42(4). Available from: http://www.isc.hbs.edu/econ-innovative.htm [Accessed: 12th June 2010]

[23] Shklar, L., Rosen, R., (2007) Web application architecture: principals, protocols and practices. 2nd ed. Essex: John Willy \& Sons

[24] Tzu S. et al (1910) The art of war, France: PaxLibrorum (e-book)

[25] Victorino, L. et al (2005) Service innovation and customer choices in the hospitality industry: managing service quality. 15(6), pp. 555-576

[26] Vogt, E. et al (2003) The art of powerful questions: Catalyzing Insight, Innovation and action. 1st ed., USA. Whole systems associates. 